This document is confidential and is proprietary to the American Chemical Society and its authors. Do not copy or disclose without written permission. If you have received this item in error, notify the sender and delete all copies.

\title{
A Study of the Effect of Anisotropic Gold Nanoparticles on Plasmonic Coupling with a Photosensitizer for Antimicrobial Film.
}

\begin{tabular}{|r|l|}
\hline Journal: & ACS Applied Bio Materials \\
\hline Manuscript ID & mt-2019-008389.R2 \\
\hline Manuscript Type: & Article \\
\hline Date Submitted by the & $\mathrm{n} / \mathrm{a}$ \\
\hline Complete List of Authors: & $\begin{array}{l}\text { Rossi, Francesco; University College London, Physics \& Astronomy } \\
\text { Khoo, Eng Huat; Institute of High Performance Computing, } \\
\text { Su, Xiaodi; Institute of Materials Research and Engineering, } \\
\text { Thanh, Nguyen; University College London, Biophysics Group, } \\
\text { Department of Physics and Astronomy }\end{array}$ \\
\hline
\end{tabular}

\section{SCHOLARONE ${ }^{m}$ Manuscripts}




\title{
A Study of the Effect of Anisotropic Gold Nanoparticles on Plasmonic Coupling with a Photosensitizer for Antimicrobial Film.
}

\author{
Francesco Rossia, ${ }^{a, b,}$, Eng Huat Khoo ${ }^{d}$, Xiaodi Su $^{c, e, f^{*}}$ and Nguyễ T. K. Thanh ${ }^{a, b^{*}}$
}

a. Biophysics Group, Department of Physics \& Astronomy University College London Gower Street, London WC1E 6BT, UK.

b. UCL Healthcare Biomagnetic and Nanomaterials Laboratory, 21 Albermarle Street, London W1S 4BS

c. Institute of Materials Research and Engineering, A*STAR (Agency for Science, Technology and Research), 2 Fusionopolis Way. Innovis, \#8-03, Singapore, 138634

d. Institute of High Performance Computing, Electronics and Photonics Department, 1 Fusionopolis Way. Connexis North, \#16-16, Singapore, 138632

e. Department of Chemistry, National University of Singapore, Block S8, Level 3, 3 Science Drive 3, Singapore 117543

f. School of Engineering and Science, University of the Sunshine Coast, 90 Sippy Downs Dr, Sippy Downs QLD 4556, Australia

*corresponding author: ntk.thanh@ucl.ac.uk; xd-su@imre.a-star.edu.sg

KEYWORDS: Plasmonic coupling, anisotropy, light-activated, simulations, antimicrobial surface, non-contact sterilization.

ABSTRACT: Development of antimicrobial surfaces for sterilization is much needed to avoid the spreading of drug resistant bacteria. Light can activate antimicrobial surfaces by an interaction between nanoparticles and a photosensitizer dye, to produce a steady and efficient killing of bacteria. 
The film studied in this work contains gold nanorods (AuNRs) of $32 \mathrm{~nm}$ length and $16 \mathrm{~nm}$ diameter and gold nanostars (AuNSs) of $50 \mathrm{~nm}$ of diameter, in combination with crystal violet dye (CV). The surface plasmon resonance (SPR) of the nanoparticles used in the film was mathematically simulated and characterized to understand difference SPR between the particles. Their effects on plasmonic coupling with the dye, thus the production of reactive oxygen species (ROS) and consequently the activity of the film against bacteria were studied. The films showed great antimicrobial activity against gram negative bacteria (E. coli) in $4 \mathrm{~h}$ of light exposure, when modified with AuNSs, it could kill E. coli in 5 orders of magnitudes (5$\log$ ) and the one modified with AuNRs could kill with 4 order of magnitudes (4-log). While maintaining partial activity against gram positive bacteria (S. aureus), i.e. being able to kill in 2.5 orders of magnitudes by the film containing AuNSs and 3 orders of magnitudes by those containing AuNRs. The differential response of gram (-) and gram (+) bacteria to the ROS generated by the films, would allow more targeted approach for specific bacterial species, for example, surfaces of bedpans or common contact surfaces (handles, handrails etc.) that are contaminated principally by gram (-) or gram $(+)$ bacteria, respectively.

\section{INTRODUCTION}

The increased occurrence of infections caused by drug resistant bacteria has caused a worldwide drain of resources for the health systems around the world. In the 2013 alone, in the US there were 2 million of reported cases of infections from resistant bacteria leading to 23000 causalities and costed 55 billion USD. ${ }^{1}$ While in the European Union, during the 2017, they caused 33000 causalities and a total burden on the health system of 1.1 billion EUR. ${ }^{2}$ A current strategy to fight this kind of infections is to improve the capability to disinfect the environments, especially if exposed to high concentrations of drugs, as for example medical equipment and surgical theatres. ${ }^{3}$ Routine disinfection methods, e.g. wiping with detergents and disinfectants, they are not completely effective and require a constant effort to maintain an acceptable sterility level. ${ }^{4,5}$ During terminal sterilization procedures, high intensity contactless disinfection methods are used to improve on the performances of the routine sterilization. But these methods require high energy treatments (UVB, UVC) ${ }^{6}$ or the use of chemicals (hydrogen peroxide, chlorine releasing agents, chemical fogging) ${ }^{7,8}$ which shorten the lifetime of the surfaces in the sterile environment and limit the access to the area while in use. ${ }^{9}$

A different approach to obtain sterility is the development of antimicrobial surfaces or films. These kind of surfaces/films, when activated, generate a continuous antimicrobial effect that progressively eliminates the bacteria on their surface. ${ }^{10}$ Some types of antimicrobial films are 
able to kill bacteria by slowly releasing active substances (e.g. antibiotics, enzymes or metal ions). ${ }^{7} \mathrm{~A}$ drawback of this kind of surfaces is that exposing the bacteria to small doses of the antimicrobial agents protracted in time can trigger the development of bacteria resistance and loose efficiency with time. ${ }^{11}$ Some instead, require laser light or UV lamps to be activated, thus reducing their convenience as alternative to the terminal sterilization. ${ }^{12,13}$

More recently a variety of light activated polymer films have been developed, exploiting spherical gold nanoparticles $(<5 \mathrm{~nm})$ to catalyze the production of radicals from a proximal photosensitizer dye. These films require no laser but need at least $6 \mathrm{~h}$ of light exposure to reach 3 to 4 order of magnitudes of bacteria reduction. ${ }^{14}$ Introducing rod shaped gold nanoparticles (gold nanorods), instead of spherical particles, inside the polymeric matrix boosted the production of oxygen reactive species (ROS) throughout plasmonic coupling with the photosensitizer dye. The resulting film was able to double the bacterial reduction efficiency, i.e. achieving 3-4 order of magnitudes of E. coli reduction in only $3 \mathrm{~h}$ of exposure to white light. ${ }^{15}$

To further increase the antimicrobial efficiency, in this work, for the first time, gold nanostars (AuNSs) were introduced in the polymeric matrix containing crystal violet, with the attempt to boost the amount of ROS generated. The electromagnetic distribution caused by the surface plasmon resonance (SPR) along the shapes of anisotropic AuNSs was characterized by mathematical simulation and empirical study. For comparison and to better understand the importance of anisotropic plasmonic coupling to produce the antimicrobial effects, rod shaped gold nanoparticles (AuNRs) were also studied.

The films containing AuNSs or AuNRs were tested against E. coli as an example of gram negative bacteria. For the first time, a polyurethane film containing anisotropic $\mathrm{Au}$ nanoparticles and crystal violet dye were tested for its anti-bacteria function against $\mathrm{S}$. aureus as example of gram positive bacteria.

The detailed study of the chemical-physical properties of the nanoparticles embedded in the film and their interaction with the dye was performed to better understand the efficiency of the ROS production of the films and how it affects the activity of the film against different types of bacteria.

\section{MATERIAL AND METHODS}

The full list of the reagents used in this work have been reported in the supporting information (Section S1).

\subsection{Synthesis of and Characterization Gold Nanorods (AuNRs)}


AuNRs were prepared using a modified version of the seed mediated synthesis in which the growth of the particles was driven by the presence of surfactant in solution. ${ }^{16}$ This synthesis utilized the formation of CTAB micelles in the growth solution as a mould to induce the growth of nanorods with controlled aspect ratio. ${ }^{17}$ The seeds preparation was conducted by adding 0.6 $\mathrm{mL}$ of ice cold $10 \mathrm{mM} \mathrm{NaBH}_{4}$ solution, to $10 \mathrm{~mL}$ of a solution containing $0.25 \mathrm{mM} \mathrm{HAuCl}_{4}$ and $0.1 \mathrm{M}$ of $\mathrm{CTAB}$ under fast stirring. The solution was then incubated for at least $1 \mathrm{~h}$ to obtain uniformly sized seeds throughout the Ostwall ripening process. ${ }^{18}$ The growth solution was prepared by mixing $5 \mathrm{~mL}$ of $1.4 \mathrm{mM}$ of $\mathrm{HAuCl}_{4}$, with $75 \mu \mathrm{L}$ of $10 \mathrm{mM} \mathrm{AgNO}_{3}$ and then adding $5 \mathrm{~mL}$ of $0.2 \mathrm{M}$ of CTAB followed by $0.25 \mathrm{~mL}$ of $1.25 \mathrm{M} \mathrm{NaBr}$ and $10 \mu \mathrm{L}$ of concentrated $\mathrm{HCl}(37 \% \mathrm{w} / \mathrm{w})$. The synthesis was then completed by adding $105 \mu \mathrm{L}$ of $79 \mathrm{mM}$ L-ascorbic acid followed, after $30 \mathrm{~s}$ by $60 \mu \mathrm{L}$ of seeds solution. The solution was then incubated overnight at $30^{\circ} \mathrm{C}$ to allow a consistent growth of the rods.

The presence of the surfactant electrostatically stabilized the nanorods, by forming a positively charged double layer and granting a shelf-life of more than 6 months on a benchtop at room temperature. The stability was confirmed comparing the intensity and the position of lateral and longitudinal of SPR nanorods after 6 months on benchtop (Figure S1, Supporting Information (SI)). Prior to use for preparing the polymer film, this surfactant had to be eliminated and exchanged by sodium citrate. This is to improve the biocompatibility of the nanoparticles ${ }^{19-21}$ and to increase the electrostatic interaction between the nanorods and the positive charged photosensitizer dye in the polymer matrix. The particles used as control for the simulations were instead stabilized with thiol-PEG-OMe. This polymer was used to form a neutrally charged layer while avoiding to interfere with the electrical field surrounding the particles.

CTAB was removed from the solution using centrifugation cycles $(14000 \mathrm{rpm}, 7 \mathrm{~min}$ using Mikro 220R Hettich centrifuge) to collect the particles into a pellet, which was redispersed with a series of washing solutions: water for the first passage, sodium polystyrene sulfonate (PSSNa $0.15 \% \mathrm{w} / \mathrm{w}$ ) for two cycles ${ }^{22}$ and finished with two cycles using a solution containing electrostatic (citNa $20 \mathrm{mM}$ ) or steric (thiol-PEG-OMe $15 \mu \mathrm{M}$ ) stabilizers, which granted a shelf-life of at least 2 months if stored at $4{ }^{\circ} \mathrm{C}$, after which the solutions formed visible aggregates. ${ }^{19,23,24}$

The absorption spectra of the nanorod dispersions were acquired using a Biotek Synergy 2, plate reader. Size and aspect ratio of the nanorods was determined using ImageJ software ${ }^{25}$ on 
at least 10 TEM images, each containing from 50 to 300 nanoparticles. All the images were acquired using a Philips CM300 FEG TEM operating at $300 \mathrm{kV}$.

\subsection{Synthesis and Characterization of Gold Nanostars (AuNSs)}

AuNSs were prepared using a different modification of the seed mediated synthesis compared to AuNRs. In this synthesis $10 \mathrm{~mL}$ of $0.25 \mathrm{mM} \mathrm{HAuCl}_{4}$ were acidified with $10 \mu \mathrm{L}$ of $1 \mathrm{M} \mathrm{HCl}$. To the solution was then added: $100 \mu \mathrm{L}$ of seeds solution, $100 \mu \mathrm{L}$ of $3 \mathrm{mM} \mathrm{AgNO}, 50 \mu \mathrm{L}$ of $100 \mathrm{mM}$ ascorbic acid and after $30 \mathrm{~s}, 1.74 \mathrm{~mL}$ of $7 \mathrm{mM} \mathrm{CTAB}$ to stabilize the newly formed nanostars. ${ }^{26}$ The seeds used as initiator for the nanostars growth were citrate stabilized spherical gold nanoparticles with average diameter $13 \mathrm{~nm}$ synthesized by the tri-sodium citrate reduction: $0.5 \mathrm{~mL} 1 \mathrm{wt} \%$ citrate solution was added to a boiling solution of $\mathrm{HAuCl}_{4}(9.5 \mathrm{~mL}$, $0.5 \mathrm{mM}) .{ }^{27}$ To obtain nanostars stabilized with thiol-PEGOMe, $1.74 \mathrm{~mL}$ of $15 \mu \mathrm{M}$ thiolPEGOMe was added to the growth solution instead of CTAB.

After $30 \mathrm{~min}$ from the addition of the stabilizer the particles dispersion was washed by centrifugation (6000 rpm), for $4 \mathrm{~min}$, at $30{ }^{\circ} \mathrm{C}$ using MIKRO 220R Hettich centrifuge and redispersed with water. Samples coated with thiol-PEG-OMe were stable after the first centrifugation while the batches using $\mathrm{CTAB}$ required the same series of washing procedure used for the citrate stabilized AuNRs. These cycles of centrifugation were performed at 6000 rpm for 4 min followed by twice redispersion with $0.15 \% \mathrm{w} / \mathrm{w}$ PSSNa and by stabilization with $20 \mathrm{mM}$ sodium citrate. The quality of the batches was assessed with the same set of characterisations used for AuNRs.

\subsection{Preparation of the Antimicrobial Films}

The polymeric matrix backbone of the antimicrobial film was $1 \mathrm{~mm}$ thick polyurethane (PU). It was stable in physiological condition and possessed a low adhesion coefficient quality that made it commonly used for medical application such as catheters, bandages and common touch surfaces of medical devices. ${ }^{28,29}$ The as-prepared metal nanoparticles were loaded in the PU film throughout the swelling-encapsulation-shrink method. ${ }^{14}$ This method uses $15 \mathrm{~mL}$ of a solution containing 9:1 acetone to nanoparticles dispersion (1.5 O.D.; approximatively 0.65 $\mathrm{mM}$ of $\mathrm{Au}^{0}$, the optimum concentration based on our previous study ${ }^{15}$ ) to swell $30 \mathrm{~cm}^{2}$ polymeric matrix. The swelling process required an overnight incubation under moderate magnetic stirring, in order to obtain a uniform deposition of the particles. The swollen polymer was collected from the acetone solution and washed with bi-distilled water. The remaining 
organic solvent in the film was evaporated by drying the polymer with a benchtop extractor for $3 \mathrm{~h}$ at $35^{\circ} \mathrm{C}$.

The last step of the film preparation was completed introducing the photosensitizer dye, $\mathrm{CV}$, in the polymeric matrix. The diffusion of $\mathrm{CV}$ in the polymer was induced by immersing the film in an aqueous solution of $1 \mathrm{mM}(0.41 \mathrm{mg} / \mathrm{mL})$ dye, near to the saturation concentration $\left(2.5 \mathrm{mM}\right.$ at $\left.25^{\circ} \mathrm{C}\right)$, for $48 \mathrm{~h}$ under moderate stirring ( $250 \mathrm{rpm}$, magnetic stirrer). As described in literature ${ }^{14}$, and from our own tests showed that the dye diffused in the polymer was strongly bound and did not leak out after $300 \mathrm{~h}$ exposure to aqueous solutions. Visual assessments (macroscopic change in colour of the polymeric film) and acquiring UV-visible spectra of the polymeric samples were performed (with a Biotek synergy 2 plate reader) to assure the successful preparation of the film.

\subsection{Antimicrobial Activity Test}

Samples of $1 \mathrm{~cm}^{2}$ of the film were used to test the efficiency against model gram negative and positive bacteria. E. coli (ATCC25922) and S. aureus (ATCC6538) were used to simulate the gram (-) and gram (+) population on medical surfaces. The tests were performed in an environment with controlled humidity, by resting a microscope slide containing the film samples, on the water surface $(2 \mathrm{~mL})$ in a $10 \mathrm{~cm}$ petri dish, then inoculating the film tiles with $25 \mu \mathrm{L}$ solution containing $10^{8} \mathrm{cfu} / \mathrm{mL}$ of bacteria. Thus, obtaining an initial bacterial load of $2.5 \times 10^{6} \mathrm{cfu} / \mathrm{cm}^{2}$. The lamp used for the test was a $28 \mathrm{~W}$ Wattmiser GE lamp, a commercially available neon lamp commonly used in public building and able to generate a light intensity of 11.7 klux. The test was performed on multiples samples of antimicrobial film in triplicates for a minimal amount of repetitions of 12 for every conditions.

During the exposure time, the samples were covered with a coverslip to limit the loss of humidity and increase the contact of the solution with the polymer. When the exposure time for a given sample was achieved, film tiles and coverslips were placed in a $50 \mathrm{~mL}$ centrifuge tube and washed using $2 \mathrm{~mL}$ of a sterile solution of $0.9 \% \mathrm{w} / \mathrm{w}$ of $\mathrm{NaCl}$ to collect the surviving bacteria. The resulting solution was diluted to a suitable concentration (calculated from the initial concentration of bacteria) and plated on nutrient agar plate. After overnight incubation of the plates at $35^{\circ} \mathrm{C}$, the colonies formed by the bacteria were counted and their number was used to estimate the efficiency of the system. ${ }^{30}$

\subsection{Confirmation and Assessment of the Production of ROS}


The amount of ROS generated by the film was estimated exploiting the property of sodium fluorescein of having a reproducible fluorescence quenching when exposed to light and to loose quickly fluorescence intensity when the exposure to free radicals converted it to the oxidized form. ${ }^{31-33}$ The fluorescein quenching was used in this work to quantify the ROS production of the films. ${ }^{15}$

The test was performed on a solution containing $0.13 \mu \mathrm{M}(50 \mu \mathrm{g} / \mathrm{mL})$ of sodium fluorescein alkalinized with $5 \mathrm{mM} \mathrm{NaOH} .{ }^{31,32}$ This solution was exposed to light for $1 \mathrm{~h}$ on the surface of the film in a similar set up with the antimicrobial tests. The fluorescence intensity of the samples exposed to light on the modified polymer (PU/CV, PU/citNa-AuNRs/CV and $\mathrm{PU} / \mathrm{citNa}-\mathrm{AuNSs} / \mathrm{CV}$ ) was compared with the intensity of the solution exposed on the unmodified (control) polymer (PU). The concentration of quenching agent in solution was calculated using the difference of fluorescence intensity between samples and controls according to the Stern-Volmer equation, ${ }^{34}$ reported in the discussion part. During the emission of fluorescence, fluorescein decay from the excited state of triplet to a stable singlet state. In alkaline conditions and in presence of ROS the excited form of fluorescein was oxidized to a less fluorescent form, thus reducing drastically the fluorescence emission. Both the solutions exposed to the modified film and the control were tested at the same time, excluding the interferences caused by the experimental conditions and the regular photobleaching of the solution. ${ }^{35,36}$ To confirm the results obtained throughout the Stern-Volmer equation, a calibration curve was prepared by exposing fluorescein solution to light for $1 \mathrm{~h}$ (11.7 klux), and then adding to it increasing concentrations of $\mathrm{H}_{2} \mathrm{O}_{2}(1,5,7.5,10,12.5 \mathrm{mM})$. $\mathrm{H}_{2} \mathrm{O}_{2}$ in alkaline condition existed in equilibrium with two radical forms $(\cdot \mathrm{OOH}, \cdot \mathrm{OH})^{37}$ and was used to simulate the effect of the ROS generated by the film during the light exposure. The fluorescein solutions were tested after overnight incubation because the quenching process depended on the impact between activated fluorescein and one of the radical forms of $\mathrm{H}_{2} \mathrm{O}_{2} .{ }^{33,38}$ The fluorescence measurements were performed with a Biotek plate reader using the same conditions reported in our previous work F. Rossi (2019). ${ }^{15}$

\subsection{Simulation of the SPR of the Nanoparticles}

The simulations were performed with a Lumerical finite-difference time-domain (FDTD) software, capable of mathematically calculating the solutions for the Maxwell equation of nano-plasmonic objects, in a tri-dimensional space. ${ }^{38}$ The FDTD method subdivided the environment of the simulation in cubic three-dimensional regions and assign to them properties 
as material, refractive index, polarization and used to map the response of the system to a phenomenon progressing in time (as the resonance of electrons in a particle).

The size of these spatial subdivisions depended on the size of the object studied and by the definition necessary to obtain good quality results. For a typical FDTD experiment the side of the cubic volume was between $1 / 10-1 / 20$ of the size of the objects analysed, for the simulation used in this article, the sides of the volumetric unit were of $1 \mathrm{~nm}$ of length. Using small volume units allowed to simulate nanoparticles with complex shapes, stars and rods, and their stabilizing agents. To improve the visualization of the electrical field generated by the SPR of the particles, the space surrounding the particles, was consider filled with a uniform polarizable media, water with refractive index 1.33 and the particles were considered as stabilized sterically with a thin layer of thiol-PEG-OMe to avoid all the electrostatic interaction not derived from the resonance of the electrons. The stabilizing layer was considered thin enough to not interfere with the environment to be simulated (images of the simulation boxes reported in Figure S2, SI). The nanostructures are modelled as gold material. Simulations boundary conditions are carried out using perfectly matched layers (PML). The simulated systems were tested after the excitations with two different wavelengths, named $\mathrm{x}$ and $\mathrm{y}$, these source inputs were plane waves of polarized light comprised from $400 \mathrm{~nm}$ to $900 \mathrm{~nm}$ of wavelength range.

\section{RESULTS AND DISCUSSION}




\subsection{Characterization of As-Prepared AuNRs and AuNSs}
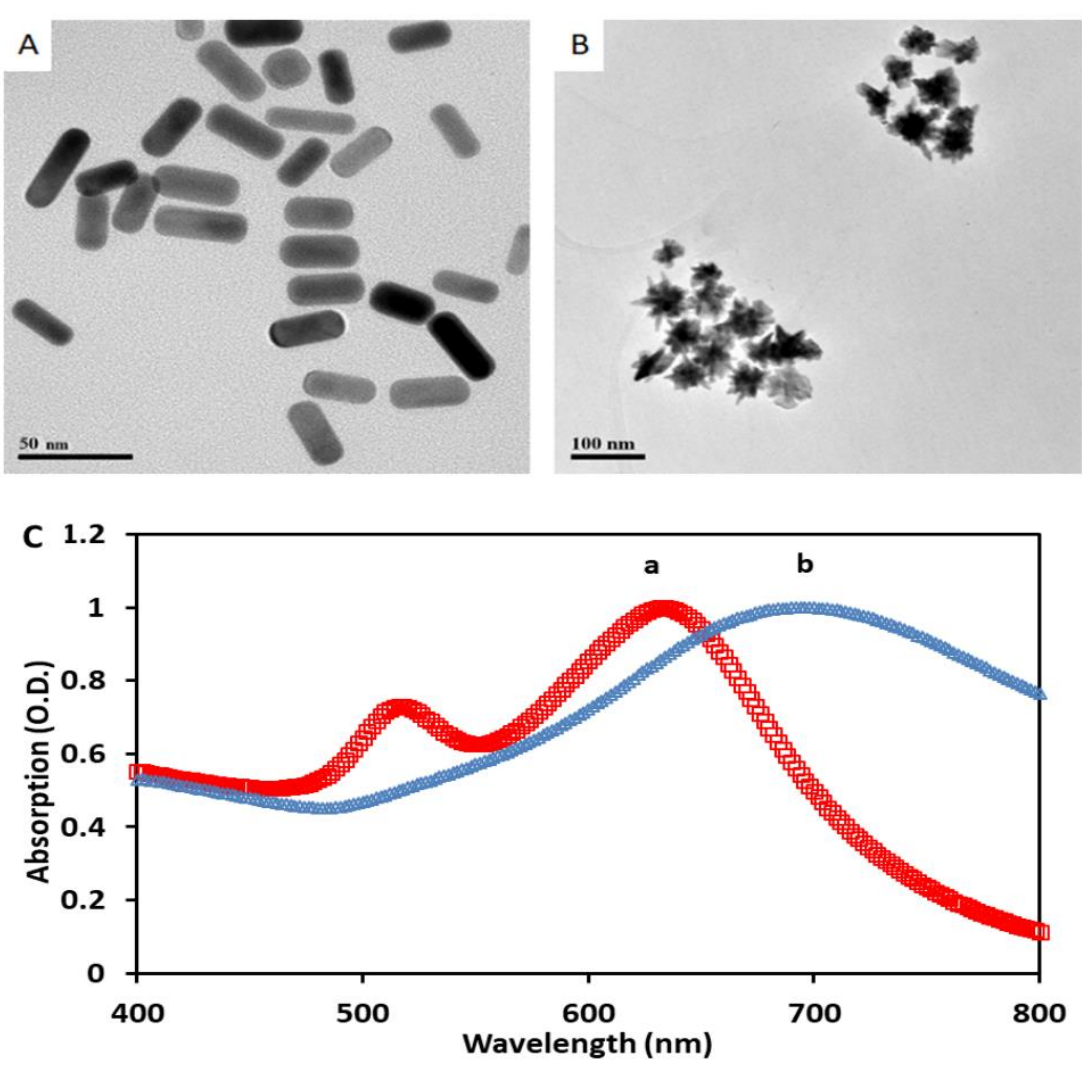

Figure 1. Characterization of AuNRs and AuNSs: A) TEM picture of AuNRs 75k magnifications, B) TEM picture of AuNSs $23.5 \mathrm{k}$ magnifications and C) UV-visible spectra of citNa-AuNRs (a) and citNa-AuNSs (b).

The as-prepared gold nanorods (AuNRs) have an average length of $31.8 \pm 6.4 \mathrm{~nm}$ and $16.1 \pm$ $3.7 \mathrm{~nm}$ in diameter, resulting in an average aspect ratio of $2.1 \pm 0.2$. The gold nanostars (AuNSs) have a star like structure with a central core of $35.6 \pm 7.9 \mathrm{~nm}$ from which several spikes emerge. These spikes could vary in length and thickness, with an average value of 16.1 $\pm 5.1 \mathrm{~nm}$ with a base diameter that could vary between $5-10 \mathrm{~nm}$ and a tip diameter of 1 to 3 $\mathrm{nm}$. The size of AuNSs (core and spikes) could be approximated to $60 \mathrm{~nm}$ sphere, but they possessed a much larger surface area and SPR intensity. The Au NSs has the bulk of the mass concentrated in the core, which has similar size with the length of AuNRs. The physical dimensions of the particles were extrapolated by the analysis of a collection of TEM pictures (Figure 1, A and B), analysed with ImageJ software (TEM images with lower magnification in Figure S3, SI). The UV-visible spectra of both AuNRs and AuNSs were acquired to control the quality of the batches (Figure 1, C). AuNRs had two intense and defined surface plasmon resonance (SPR) absorption peaks at $520 \mathrm{~nm}$ and $620 \mathrm{~nm}$. The absorption peak the shorter 
wavelength was generated by the lateral SPR of AuNRs, while the second at $620 \mathrm{~nm}$ was connected to the longitudinal SPR. The AuNSs instead had an intense and broad absorption peak from 620 to $780 \mathrm{~nm}$, due to the complex interaction between the resonance of the star core and the electrical field of the spikes and from the wide dispersion of spike dimensions.

\subsection{Nanoparticles SPR Simulation}

The influence of the SPR on the absorption peaks of the particles and the effect on the electrical field surrounding them was mathematically simulated in order to predict their intensity of their plasmon coupling with the dye. As reference for the simulations, samples stabilized with thiolPEG-OMe were prepared and analysed with UV-visible. Compared with the samples stabilized with citNa, the absorption peaks of the samples stabilized with thiol-PEG-OMe were redshifted of approximately $10 \mathrm{~nm}$ (Spectra of the particles with different stabilization costings in Figure S4, SI).

\subsubsection{SPR simulation of AuNRs}

The spectra of the AuNRs samples were easier to simulate, showing only few nanometres of deviation between the predicted longitudinal SPR and the spectra of the rods synthetized.

The inset is the near field distribution of the nanorods, excited by $\mathrm{x}$ and y polarization and the perfectly matched layer (PML) boundary conditions were applied to the

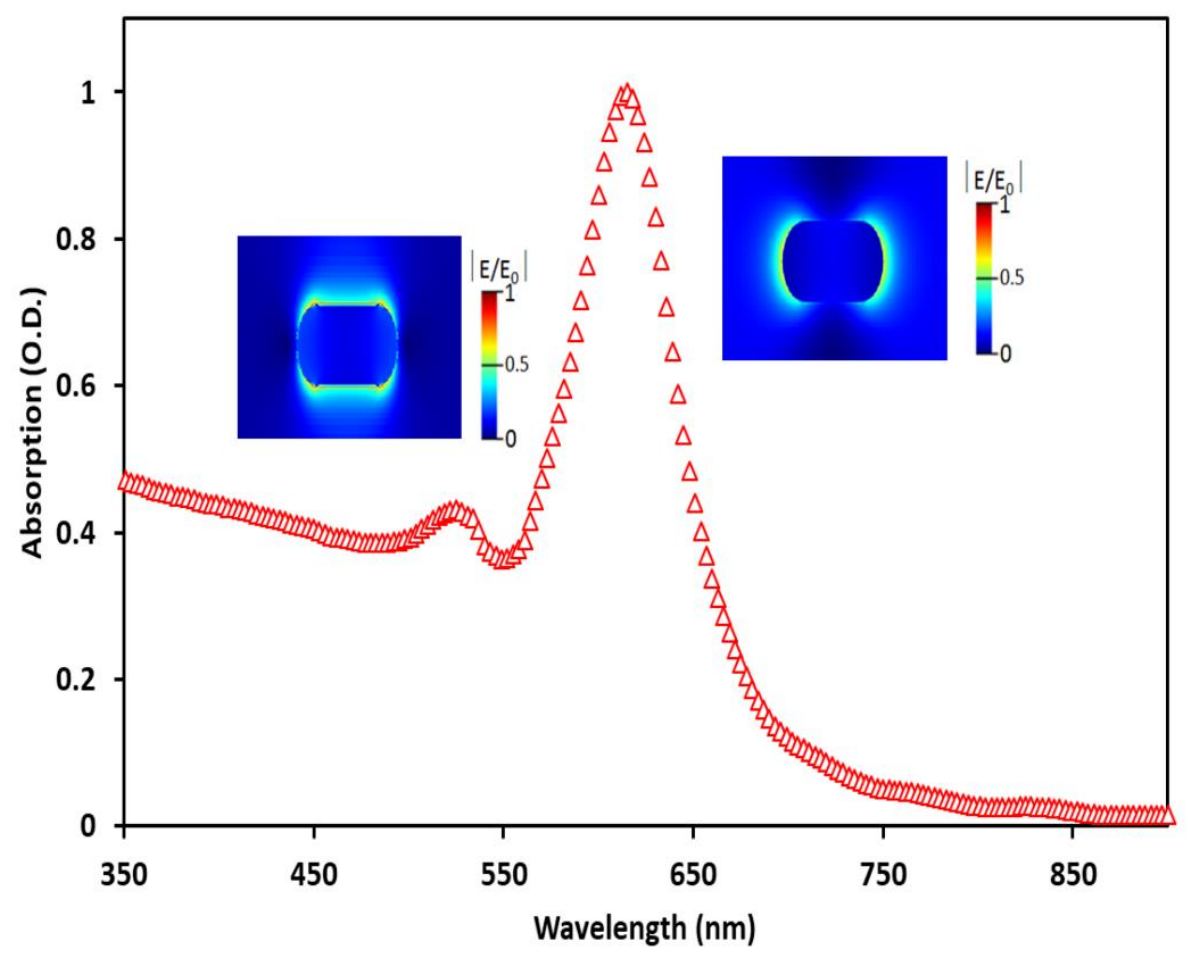

Figure 2. Electrical field simulation for AuNRs (31.8 $\mathrm{nm} \times 16.1 \mathrm{~nm}$ ) stabilized with thiol-PEG-OMe. 
simulation. The y polarized light interacted with the lateral SPR resulting in a peak at $525 \mathrm{~nm}$ while the $\mathrm{x}$ polarized light interacted with the longitudinal SPR resulting in the peak at $615 \mathrm{~nm}$. The mesh size is $1 / 20$ of the excited wavelength. The entity of the electrical field was depicted in the graphical representation of the simulation as a bright coloured area around the shape of the nanorods (Figure 2).

Crystal violet has two convoluted peaks at 520 and $590 \mathrm{~nm}$ respectively. The absorption peaks of CV fitted exactly in the area of the spectra between the two SPR peaks of the AuNRs partially overlapping with both the lateral SPR and the longitudinal SPR (Figure S5, SI). It has been shown from previous work that the electrostatic interaction brings the dyes and the AuNRs together. ${ }^{15}$ The overlapping between the absorption of the SPR peaks of AuNRs indicated by the simulation and the dye absorption confirm that all the components of the spectra, can participate in the plasmonic coupling with the dye. Thus, when located in close proximity inside the polymeric matrix boost the ROS production of the antimicrobial film.

\subsubsection{SPR Simulation of AuNSs}

The spectra obtained by the simulation of AuNSs was more difficult to interpret. The spectrum of the AuNSs showed a broad peak between 620 to $780 \mathrm{~nm}$.
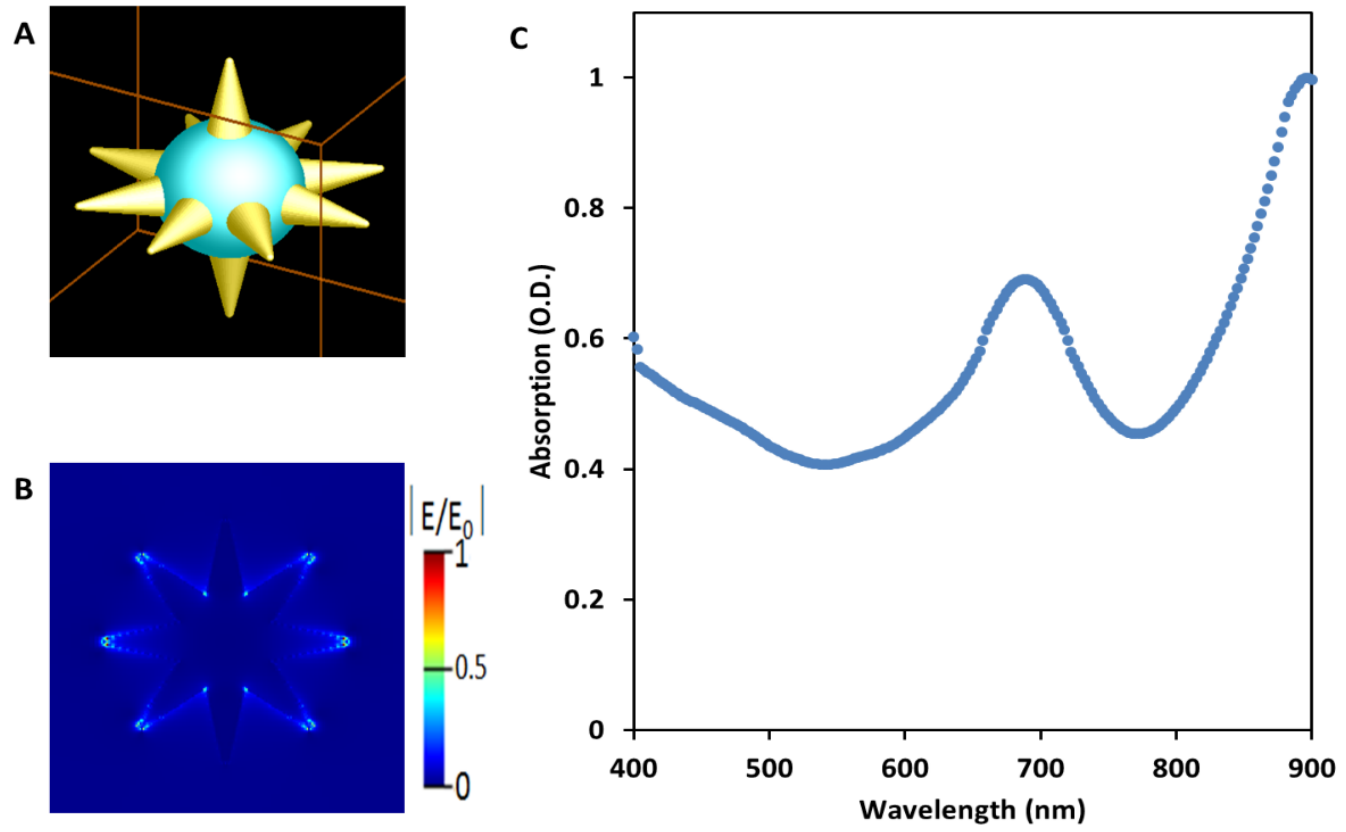

Figure 3. Simulation of the SPR of the electrical field around AuNSs with 35.6 $\mathrm{nm}$ core with $16.1 \mathrm{~nm}$ spikes, stabilized with PEG. A) Model of the nanostar used in the simulation; B) Graphical representation of the potential fluctuation of the electrical field on the surface of the particles; C) Simulated spectrum of the nanostars dispersion. 
The simulations instead indicated the presence of multiple peaks, generated by the resonance of the electrical field surrounding the various features of the nanostar structure (e.g. core, spikes). The first simulation in Figure $3 \mathbf{C}$, represents nanostars with the average core size and spike length obtained by TEM (aspect ratio core: spikes $=2.1$ ). The application of $\mathrm{x}$ and $\mathrm{y}$ wavelengths to AuNSs, with aspect ratio 2.1, resulted in two resonance peaks. The first for the fluctuation of the electrical field on the entire spikes systems $(690 \mathrm{~nm}$, excited by $\mathrm{x}$ polarization) and the second at $900 \mathrm{~nm}$, excited by y polarization, which represent the situation in which the electrical field is mostly concentrated on the tips of the spikes (Figure 3 B). This last peak near $900 \mathrm{~nm}$ does not show on the absorption of the AuNSs in solution. The first simulation was able to present the position of the main peak, but it couldn't completely account for the spectra of the AuNSs in solution. The first simulation was able to describe the position of the main peak, but it couldn't completely represent the spectra of the AuNSs in solution.In order to see which part of the absorption spectrum was due to the resonance of the core and which to the spikes another simulation for AuNSs with aspect ratio between core and spikes 5:1. This simulation was divided into two spectra: i) for the spikes (Figure 4 A) and ii) for the core (Figure 4, B).

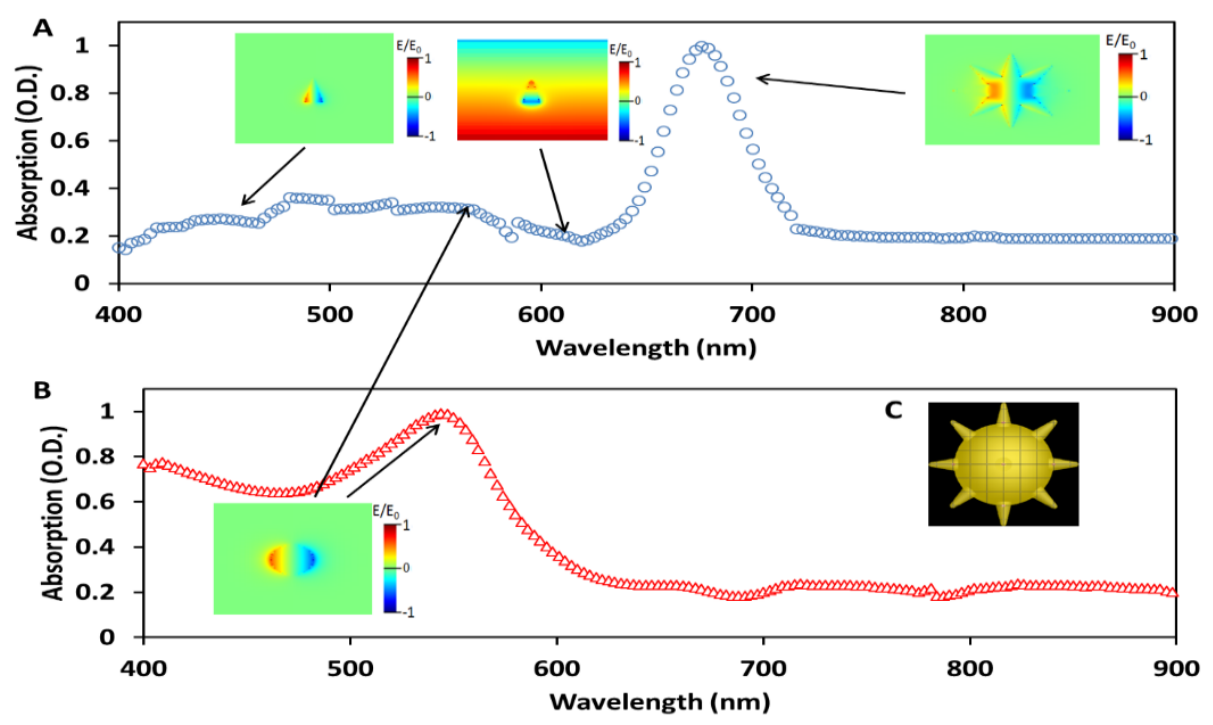

Figure 4. Electrical field resonance simulation for AuNSs (50 nm core with $10 \mathrm{~nm}$ spikes) stabilized with PEG A) simulated spectra of the spike system and B) simulated spectra of the core C) model of the AuNSs used for the simulation.

The insets are the near field distribution of the spike and core excited by $\mathrm{x}$ and y polarization. The application of both $\mathrm{x}$ and $\mathrm{y}$ polarized light to the model resulted in the appearance of three peaks in the spectrum shown in Figure 4A and a peak for the AuNSs core in Figure 4B. The simulation modelled on AuNSs with aspect ratio 5:1 identified four possible resonances: i) the 
resonance of the spikes as single objects $(428 \mathrm{~nm})$, ii) the electrical field along the length of the spikes $(585 \mathrm{~nm})$ and iii) the resonance of the core at $534 \mathrm{~nm}$ (which is comparable with the resonance of a spherical particle of the same size) and iv) the resonance of the entire spikes system at $658 \mathrm{~nm}$. The resonance of the core and of the single spikes were excited by the $\mathrm{x}$ polarization while the resonance on the length of the spikes and of the entire spikes system was excited by the y polarization wave.

The spectrum of the as-prepared AuNSs acquired experimentally (Figure 1, C) showed a single broad peak between $620 \mathrm{~nm}$ to $780 \mathrm{~nm}$, with maximum centred at $700 \mathrm{~nm}$. The peak showed by the real sample contained, convoluted all the single components identified by the simulations (Figure S6, SI) with the only exception of the peak at $900 \mathrm{~nm}$ which did not correspond to the range of absorption of the real sample. While the predominant component of the spectrum, according to the simulation was the resonance of the electrical field on the entire spike system, identified by the peaks at $658 \mathrm{~nm}$ and $690 \mathrm{~nm}$ in the two simulations.

The absorption of CV in the polymer overlapped completely with the SPR resonance of the AuNSs core and with the resonance of the field along the length of the spikes (Figure S6, SI) and partially with the resonance on the entire spike system. The large overlapping between the spectra explained the plasmonic coupling between dye and particles and consequently the increase of ROS production for a film containing both.

\subsection{Characterization of the Antimicrobial Films}

As described in the experimental section the particles were embedded in PU film using the swell-encapsulation-shrink method while the dye was introduced successively. Both the stages of the film preparation were characterized by macroscopic changes, that could be tracked by visual observation. Particularly, the film was light yellow and transparent before the process. It turned to faint green-blue after introducing the nanoparticles and finally intense blue-purple with the dye introduction. The change of colour caused by the dye was visible throughout the whole thickness of the polymer confirming that the nanoparticles embedded in the film were all exposed evenly to the dye. Using UV-visible spectroscopy, it was possible to assess in details the film preparation results and to gain further insight in the interactions between the $\mathrm{CV}$ and the nanoparticles when both the components were introduced in the polymeric matrix..$^{40}$

\subsubsection{Characterization of the Nanoparticles Embed Films}


The nanoparticles embedded in the film gave the polymer a faint green-blue colour. The characteristic absorption peaks of the gold nanoparticles from the UV-visible spectra of the particle embedded films (Figure 5) revealed the presence of the particles, despite of minor aggregation phenomena that radically modify the SPR resonance of the nanoparticles. ${ }^{41,42}$ The spectrum of the unmodified polymer was subtracted from the spectra of the films containing
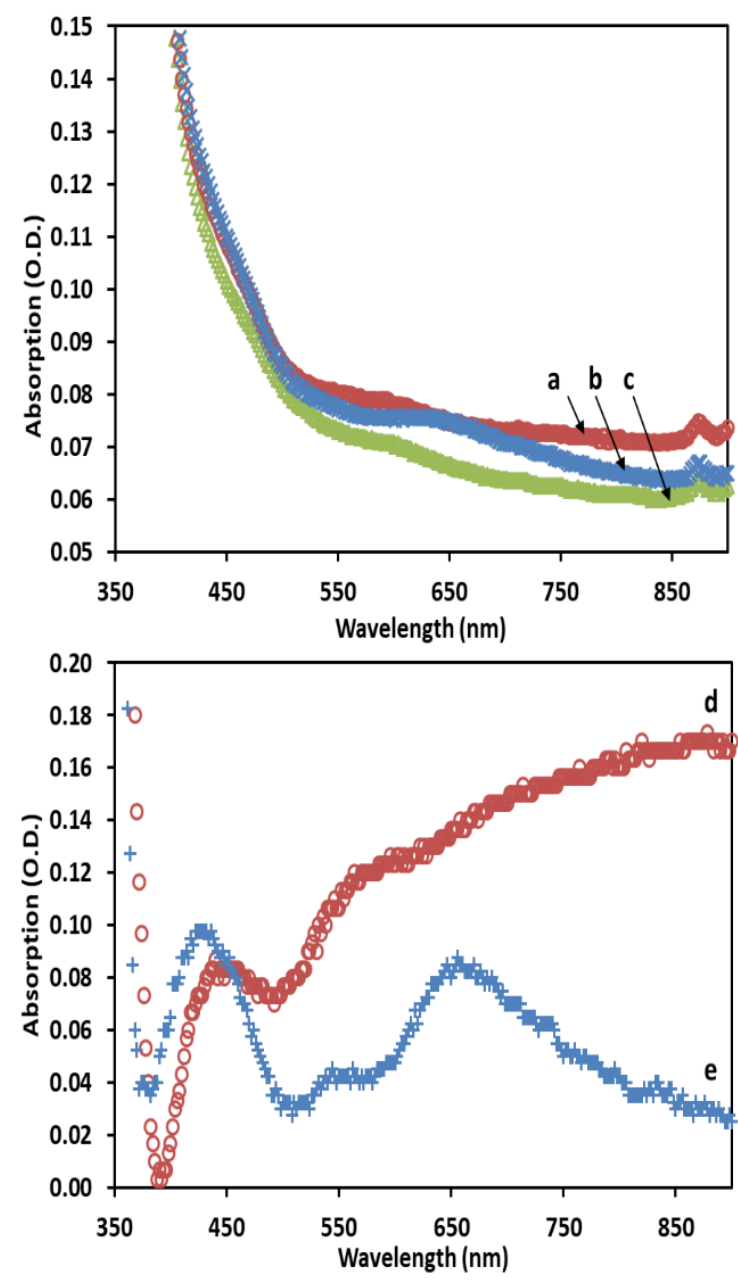

Figure 5. UV-visible spectra of a) PU/citNa-AuNSs, b) PU/citNa-AuNRs, c) PU, d) subtraction curve between PU/citNa-AuNSs and PU, and e) subtraction curve between PU/citNa-AuNRs and PU.

Au nanoparticles, the differences between the spectra were reported in the subtraction curves PU/citNa-AuNSs - PU (Figure 5, d) and PU/citNa-AuNRs - PU (Figure 5, e). Particularly, the introduction of nanoparticles in the film increased the light absorption in the range between 400 and $500 \mathrm{~nm}$ with peaks at $440 \mathrm{~nm}$ for nanorods and $450 \mathrm{~nm}$ for nanostars. The increase of the absorption at shorter wavelengths was present for both types of nanoparticles, this absorption peak was not present for the particles in solution (Figure 1, C) and it was generated only when the nanoparticles are in the solid matrix. At longer wavelength the film modified 
with the different types of nanoparticles had different absorption peaks. Films containing AuNRs showed two peaks at 540 and $650 \mathrm{~nm}$, characteristic of these type of particles (Figure 5). The AuNRs embedded in the film were red-shifted of approximatively $20 \mathrm{~nm}$. The shift was connected to the change of the dielectric constant of the environment surrounding the particles from water to the polymer, a similar condition to the AuNRs stabilized with thiolPEG-OMe used in the simulations in which the red-shift was only $10 \mathrm{~nm}$.

Embedded nanostars instead, generated a broad increase of the absorption between 550 and $950 \mathrm{~nm}$, with bumps indicating convoluted peaks at about $540 \mathrm{~nm}$ and $652 \mathrm{~nm}$, the two wavelengths suggested by the simulation as peaks for the spherical core and the spike system, respectively. In contrast with the AuNSs in solution, the particles embedded in the polymer showed a higher absorption at longer wavelengths, that may be connected with the peak of the SPR for the electrical field concentrated on the tips of the nanostars spikes, that was identified by the simulation (900 nm, Figure 3, C) and not present for AuNSs dispersed in water. After the diffusion in the film, CV maintained a similar absorption profile as it is in solution, i.e. two intense peaks partially overlapping, as it is in solution (Figure 6, curves a and b, respectively).

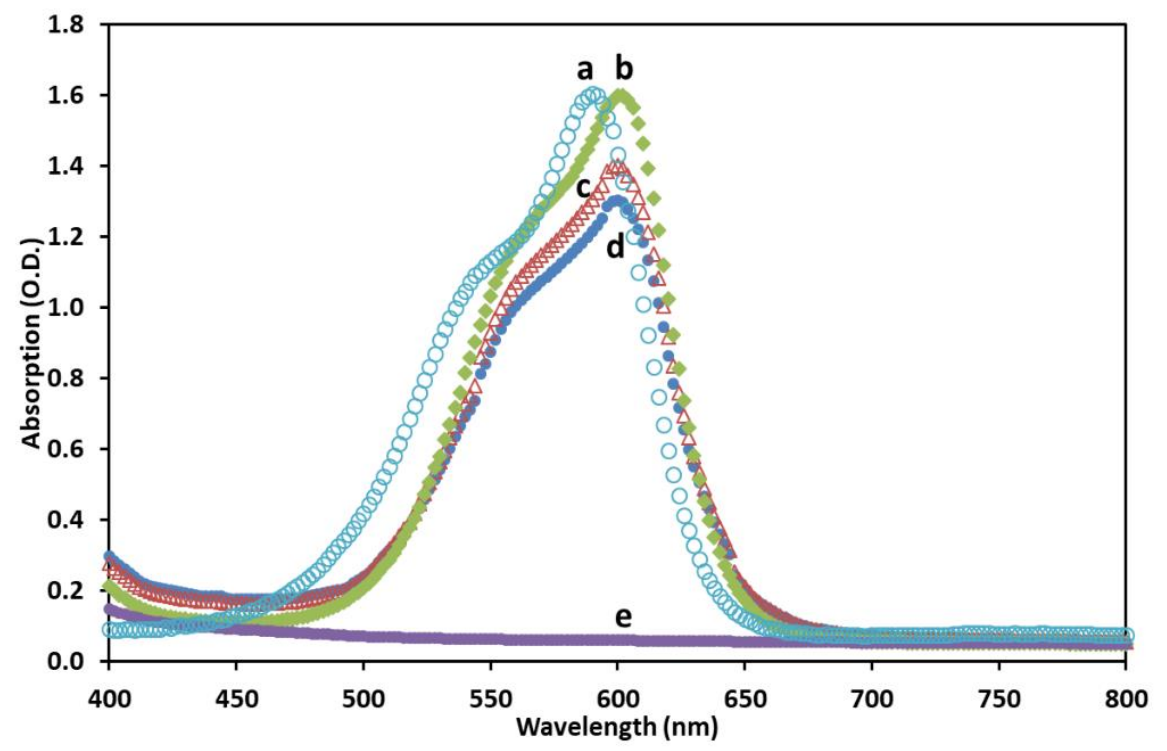

Figure 6. UV-visible spectra of a) $35 \mu \mathrm{M} \mathrm{CV}$ solution in water, b) 1 $\mathrm{mM} \mathrm{CV}$ diffused in PU for $48 \mathrm{~h}$ (PU/CV film), c) PU/citNa-AuNSs/CV film, d) PU/citNa-AuNRs/CV film and e) PU alone.

But when it is in the film the two peaks were red-shifted by $14 \mathrm{~nm}$ and the intensity ratio between them changed from $1.46(590 / 540 \mathrm{~nm}$, as in solution) to $1.28(604 / 554 \mathrm{~nm}$ in polymer). The changes in the spectrum of $\mathrm{CV}$ depended to the change in environment surrounding the dye molecules, from a polar media (water) to non-polar in solid state (film) (Figure 6, a and b). The spectra of CV diffused in films containing metal nanoparticles was slightly different to the 
dye alone (Figure 6, curves c and d). Specifically, the intensities of absorption peaks were reduced to certain degree depending on the type of particles; while the position of the peaks was red-shifted for about $12 \mathrm{~nm}$ compared to the dye in water and blue-shifted for about $2 \mathrm{~nm}$ compared to the dye alone in PU film, regardless the type of particles embedded. More precisely in presence of AuNRs the absorption peaks of CV decreased of intensity by $19 \%$ (Figure 6,d) while at the same time the plasmonic coupling between the nanorods and the dye increased the absorption at lower wavelength. While the presence of AuNSs reduced the peaks of $\mathrm{CV}$ by $7 \%$ and increased the absorption at shorter wavelength to a lesser amount compared to the nanorods (Figure 6,c) and at the same time generated an increase of absorption between 640 and $660 \mathrm{~nm}$. The changes in the absorption spectra of the film containing particles and dye, in comparison to the sum of the components ${ }^{43}$ of the film showed how the plasmonic coupling between the components of the film modify the energy absorption of the system and consequently the energy available to formation of ROS. The dye concentration in the film at the end of the incubation was estimated to be $0.345 \mathrm{mM}$, equal to $14.05 \mu \mathrm{g} / \mathrm{cm}^{2}$. This quantity was calculated using a UV-visible calibration curve of the absorption of CV in water (Figure S7 and Section S2, SI). This value of dye concentration was deemed optimal for the preparation of the film, because it was comparable (about 1:1 ratio) with the theoretical amount of gold nanoparticles introduced in the film $\left(0.323 \mathrm{mM}, 6.35 \mu \mathrm{g} / \mathrm{cm}^{2}\right)$ during the swell/shrink process, thus granting the best interaction between two components in the film. (The calculation of AuNRs concentration from 1.5 mL of 1.5 O.D. $\approx 0.65 \mathrm{mM} \mathrm{Au}^{0}$ can be seen in Section $\mathbf{S 3}$ of the SI). ${ }^{40}$

\subsection{Estimation of the ROS production}

As a measure of the efficiency of the plasmonic coupling between the embedded dye and particles, their production of ROS was measured. The production of ROS was calculated using the Stern-Volmer equation ${ }^{36}$ comparing the fluorescence of the solutions after $1 \mathrm{~h}$ incubation with PU with the solution incubated on the modified film.

$$
\frac{I_{0}}{I}=1+\tau_{0} k_{q}[Q]
$$

Where $\mathrm{I}_{0}$, and I were the fluorescence intensity of the solution after the exposure to light on unmodified polymer and the analysed film, respectively. $\tau_{0}$ was the fluorescence decay rate at $25^{\circ} \mathrm{C}$ in absence of a quencher $(3.6 \mathrm{~ns})$ and $\mathrm{k}_{\mathrm{q}}$ was constant of quenching at $25^{\circ} \mathrm{C}$ for a process involving only two molecules (fluorescein and ROS). ${ }^{36}$ According to the equation the 
production of the film modified with $\mathrm{CV}$ was of $3.03 \pm 0.60 \mathrm{mM}$ of ROS, that increased to 5.24 $\pm 0.02 \mathrm{mM}$ or $5.92 \pm 0.26 \mathrm{mM}$ with the introduction of PU/citNa-AuNRs/CV or PU/citNa$\mathrm{AuNSs} / \mathrm{CV}$, respectively.

The results obtained through the Stern-Volmer equation were confirmed by comparing them with a calibration curve obtained by adding to the solution exposed to light for $1 \mathrm{~h}$ of different concentrations of $\mathrm{H}_{2} \mathrm{O}_{2}(12.5 \mathrm{mM}, 10 \mathrm{mM}, 7.5 \mathrm{mM}, 5 \mathrm{mM}, 1 \mathrm{mM}) . \mathrm{H}_{2} \mathrm{O}_{2}$ was used as source of radical species because this molecule in the conditions of the experiment could decompose or react with organic molecules and metal ions, generating radical species. ${ }^{44}$ In the alkaline condition used in the experiment, $\mathrm{H}_{2} \mathrm{O}_{2}$ was relatively stable and interacted with the activated state of the fluorescein converting it to the oxidized form which possessed a weaker fluorescence intensity. ${ }^{45}$ The reaction between fluorescein and hydrogen peroxide was relatively slow and required an overnight incubation to reach completion. ${ }^{46}$ The concentration of ROS produced by the films according either according to the Stern-Volmer equation or the calibration curve (Figure 7) were comparable: PU/CV $2.24 \pm 1.93 \mathrm{mM}$ (Figure 7, b), PU/citNaAuNRs/CV $5.32 \pm 2.65 \mathrm{mM}$ (Figure 7, c) and PU/citNa-AuNSs/CV $6.60 \pm 2.87 \mathrm{mM}$ (Figure $7, d)$.

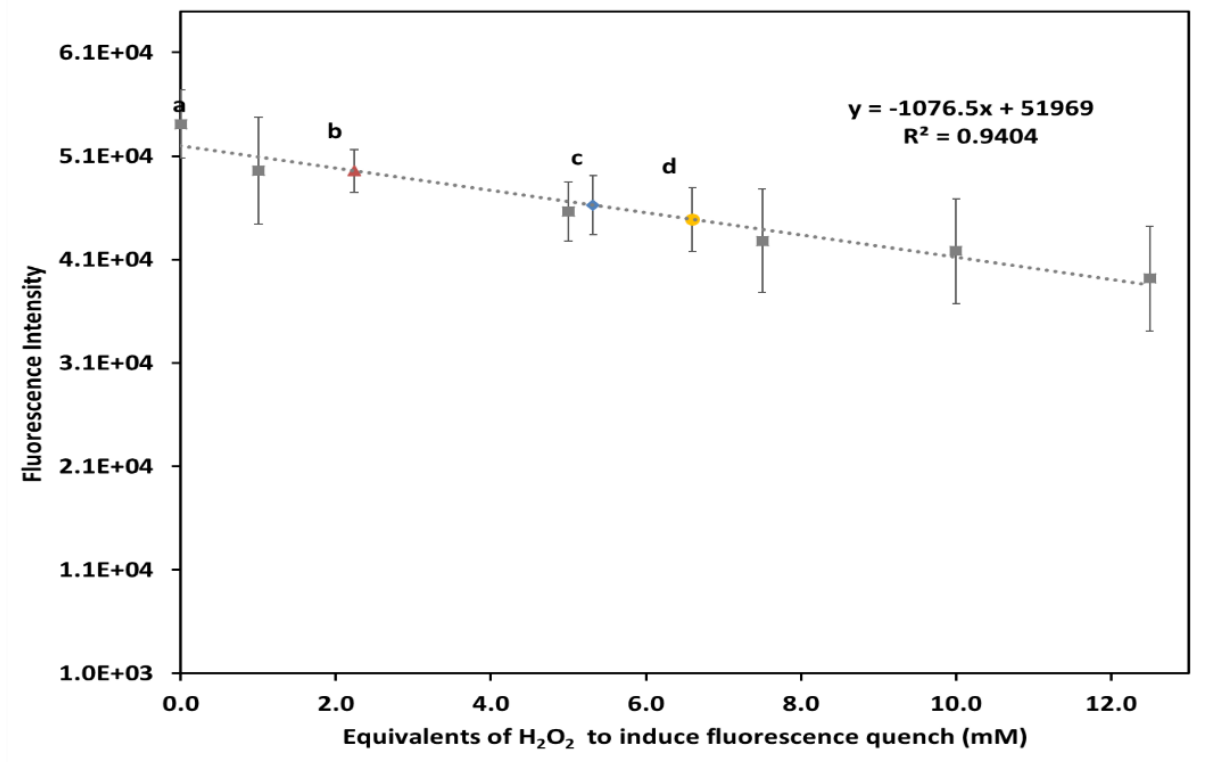

Figure 7. Fluorescence intensity against the estimated concentration of ROS by measuring the intensity of sodium fluorescein solution in the presence of different concentration of a) $\mathrm{H}_{2} \mathrm{O}_{2}$, b) $\mathrm{PU} / \mathrm{CV}$, c) $\mathrm{PU} /$ citNaAuNRs/CV, d) PU/citNa-AuNSs/CV.

The value obtained through the calibration curve (Figure 7, a), had a greater variability compared to the results calculated using the equation. This was due to the accumulation of the 
errors on the points of the calibration curve with the error on the fluorescent intensity of the samples. Independently from the method used to calculate the amount of ROS generated by the film, the film samples containing anisotropic gold nanoparticles and dye showed a greater ROS production than the samples modified only with CV. According to both methods used to estimate the concentration of ROS generated, AuNSs were able to produce the largest amount. A difference of $0.72 \mathrm{mM}$ or $1.28 \mathrm{mM}$ depending on the method used for the quantification. Comparing the absorption spectra of $\mathrm{CV}$ and AuNSs were able to produce a larger amount of ROS, could relate to the components of the SPR spectra involved in the overlapping. (Figure S5). According to the simulations three of the SPR components of AuNSs overlapped with the dye: i) the resonance of the core, ii) the resonance of the spikes along their length, which both overlap completely with the dye absorption and iii) the resonance of the spike system which overlap partially (Figure S6). While the AuNRs had only two partial overlap of spectrum with the dye absorption.

\subsection{Antimicrobial activity}

The activity of the film PU/citNa-AuNRs/CV and PU/citNa-AuNSs/CV was tested against a concentration of $2.5 \times 10^{6} \mathrm{cfu} / \mathrm{cm}^{2}$ E. Coli (Figure 8) or S. Aureus bacteria (Figure 9) for $1 \mathrm{~h}, 2$ $\mathrm{h}, 3 \mathrm{~h}$ and $4 \mathrm{~h}$ exposure to light. The film was activated when exposed to a higher intensity light compared to the normal working condition in a public building ${ }^{47}$ that would only be applied during sterilization processes or during operations which needs constant sterility as a surgical procedure. Similar antimicrobial films reported in literature were able to resist for a month of continuous light exposure, ${ }^{14}$ limiting the exposure of the film to high intensity light will extend the life of the film to months of use.

Before discussing the results and the differential antibacterial action and efficiency toward the gram negative and gram positive bacteria, we first discuss the essential difference of the two types of bacteria cells.

\subsubsection{Gram negative and gram positive bacteria.}

The two species of bacteria differed in size and type of cellular membrane. E. coli is a gram negative (gram (-)) rod like bacteria with average size of $0.25 \mu \mathrm{m}$ to $1.5 \mu \mathrm{m}$. It has a double phospholipidic membrane which are separated by a peptidoglycan barrier and some nanometres of interstitial space of a few nanometres reaching a total thickness for the external bacterial barrier between 10 to $15 \mathrm{~nm} .{ }^{48}$ The complexity of outer membrane structure of gram (-) bacteria 
makes them resistant against oxidative and chemical stresses, limiting the amount of harmful substances reaching the internal and vulnerable parts of the bacteria. At the same time E. coli is able to reduce the damages caused by the contact with ROS deploying a series of metabolic processes and producing the superoxidase dismutase (SOD) enzyme to convert $\mathrm{O}_{2}$ - $^{-}$and $\mathrm{H}_{2} \mathrm{O}_{2}$, which would be dangerous to the bacteria, to water and molecular oxygen. ${ }^{49}$

S. Aureus instead is a spherical gram positive (gram $(+))$ bacteria with average diameter of 0.5 to $1 \mu \mathrm{m}$. Gram ( + ) bacteria possessed only one thick external membrane composed by multiple layers of peptidoglycans with structures composed of sugars and amino acids. This barrier could vary in thickness between 30 to $100 \mathrm{~nm}$. For gram (+) bacteria grown in harmful environments this barrier could represent $60 \%$ of the actual mass of the bacteria. ${ }^{48}$ When compared that on gram (-), the barrier of gram $(+)$ bacteria was more permeable to chemical species and more resistant to physical stresses. In order to compensate for the permeability of their barrier $S$. aureus bacteria is able to deploy a combination of defence mechanisms to reduce and contain the damages caused by the contact with ROS. One of these defences was the pale yellow pigmentation of the bacteria, caused by the presence of carotenoids, molecules possessing a large delocalized aromatic system capable of trapping radicals penetrating into the bacterial barrier. ${ }^{50}$ At the same time $S$. aureus bacteria is overproducing enzymes able to deactivate ROS and peroxides (SOD-A, SOD-M, catalase, peroxiredoxin and flavohemoglobin) and to concentrate metal ions as iron, zinc, copper and manganese, in their intracellular fluids. These transition metal ions were able to interact with free radicals and to convert them into harmless compounds. ${ }^{51}$ The exposure of the bacteria on the polymer alone to light for the longer time points (3-4 h), caused almost 1 order of magnitude reduction on their population. Therefore, polymer only was used as a control for all later experiments.

\subsubsection{Activity against $E$. coli}

As shown in Figure 8 the antimicrobial films containing both metal nanoparticles and CV dye are activity against $E$. coli comparing the films not having the two components, and with noticeable difference of activity per hour between the polymer modified with AuNRs or AuNSs. From a starting point of $2.5 \times 10^{6} \mathrm{cfu}$ of E. coli, PU films containing both rod shaped nanoparticles (AuNRs) and CV (PU/citNa-AuNRs/CV) were able to reduce the bacteria population of one order of magnitude after the first hour ( $1 \log$ unit), 2.5 - 3-log unit by the 2 $\mathrm{h}$ timepoint, 3.5-log unit after the $3 \mathrm{~h}$ and $4-\log$ unit after $4 \mathrm{~h}$ of exposure to light (Figure 8, e). 


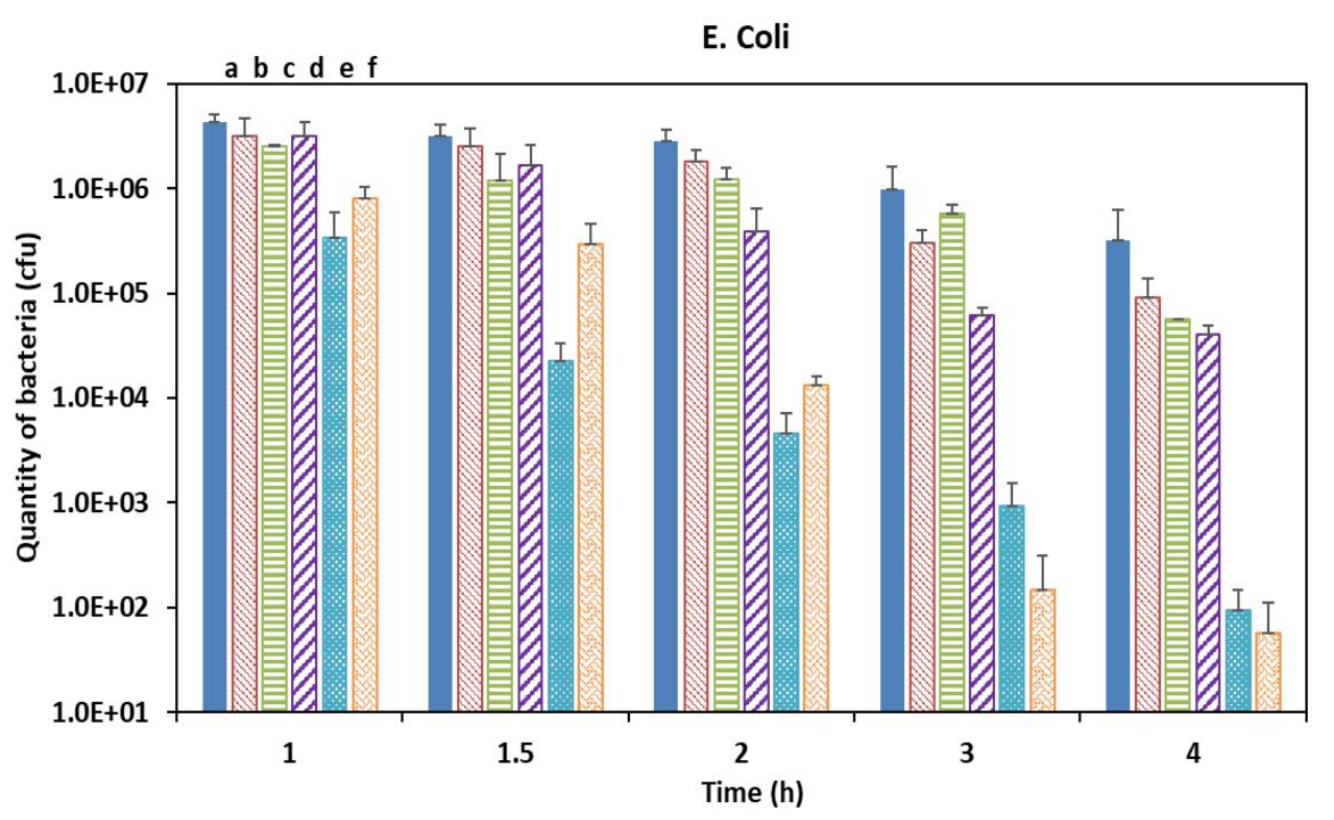

Figure 8. Antimicrobial experiments result of the antimicrobial film against $\mathrm{E}$. Coli. a) PU, b) PU/citNa-AuNRs, c) PU/citNa-AuNSs, d) PU/CV, e) PU/citNa$\mathrm{AuNRs} / \mathrm{CV}$ and f) $\mathrm{PU} / \mathrm{citNa}-\mathrm{AuNSs} / \mathrm{CV}$. All the results of $\mathrm{PU} / \mathrm{citNa}$ AuNRs/CV and PU/citNa-AuNSs/CV were statistically different compared to PU for the same time of exposure $(\mathrm{p} \leq 0.001)$

PU Film samples containing nanostars (citNa-AuNSs and CV dye (PU/citNa-AuNSs/CV) reduce $1-\log$ unit after $1 \mathrm{~h}$ of light exposure, 2-log unit after $2 \mathrm{~h}$, that stepped up to more than 4- $\log$ unit after $3 \mathrm{~h}$ and 5-log unit for the last time point (4 h) (Figure 8, f). The introduction of different kinds of nanoparticles in the film changed the efficiency and the kinetics of the antibacterial effect. AuNRs caused a quick reduction of the bacteria for the initial time points (1-log unit after $1 \mathrm{~h}, 2.5-3-\log$ unit after $2 \mathrm{~h}$ ) to slow down for the two last time points. While AuNSs generated a more limited antimicrobial effect for the first two timepoints which ramped up to reach 5-log unit for $4 \mathrm{~h}$ of exposure. The results of PU/citNa-AuNRs/CV and PU/citNa$\mathrm{AuNSs} / \mathrm{CV}$ for the last time point were close in value, because 5-log unit of reduction was near to the limit of detection of the technique used to determine the amount of bacteria surviving. As previously noted, exposing the bacteria to the light on unmodified polymer (PU) had an effect on the bacteria population generating a measurable reduction only after $3-4 \mathrm{~h}$ of exposure $(\approx 1-\log$ unit) (Figure 8, a). The film containing only nanoparticles had a limited activity, reducing the bacteria population of a quantifiable amount only for longer time points (1-log unit after $3 \mathrm{~h}$ and 1.5-log unit for $4 \mathrm{~h}$ for both AuNRs and AuNSs) (Figure 8, b and c). While the PU polymer modified with the dye only (PU/CV, Figure 8, d) retained a greater 
activity than that only has metal nanoparticles ( $\mathrm{b} \& \mathrm{c}$ ), 1-log unit for $2 \mathrm{~h}$ of exposure, 1.5-log unit for $3 \mathrm{~h}$ and 2-log unit for $4 \mathrm{~h}$ (Figure 8, d). This indicated the dye as the main source of the ROS production. To confirm the importance of using nanoparticles which had a strong anisotropy and SPR absorption overlapping to the absorption peaks of the CV (554 and 604 $\mathrm{nm}$, when in the polymer), control experiments using spherical gold nanoparticles (AuNPs) and nanorods with aspect ratio of $3-4$ (max absorption at $784 \mathrm{~nm}$ ) were performed. These experiments were conducted on E. coli for $2 \mathrm{~h}$ of exposure, conditions that were used as reference for the antimicrobial test. The first control was performed using AuNPs with average diameter of $13 \mathrm{~nm}$ and stabilized with sodium citrate, max absorption $520 \mathrm{~nm}$ (UV-vis spectra in Figure S8 of the SI). As expected from previous examples in the literature, ${ }^{13,52}$ the experiment did not revealed any improvement in the activity of the film compared to the sample modified with the CV alone. The second control contained gold nanorods (aspect ratio of 3 - 4 and max SPR absorption of $784 \mathrm{~nm}$, length $35-40 \mathrm{~nm}$, diameter $9-12 \mathrm{~nm}$, UV-visible spectra in Figure S9 of the SI). The aim of this experiment was to confirm that the overlapping of the spectra, was more important than the type of plasmonic resonance (lateral and longitudinal SPR for rods) to induce the plasmonic coupling which drove the efficiency of the system. As expected from the limited overlapping between the dye and particles absorption these samples did not generate any increases of the activity of the film compared with the samples containing the dye alone. Confirming the importance of compatible energy absorptions to trigger the plasmonic coupling between the particles and the dye (summary of the antimicrobial activity of these samples showed in the SI, Figure S10). The antimicrobial experiments and the controls performed demonstrated there was correlation between the final reduction of the gram (-) bacteria population and the production of ROS. Which resulted from the capability of the particles to interact with the excited state of the dye by plasmonic coupling. Samples modified with AuNSs produced the largest amount of ROS per hour and they had greater activity on longer exposure times of all the tested samples. While samples modified with AuNRs were able to produce slightly less ROS per hour and to kill less bacteria at the longer time points. AuNRs had lower final antibacterial effect, but they were able to have a larger effect for the shorter time points, thus suggesting that different particles had different profiles of antimicrobial activity. Samples modified with CV that had much less activity than any of any of the films containing particles due to limited ROS production.

\subsubsection{Activity against $S$. aureus}


Comparing to E Coli, the activity of the antibacterial film on S. aureus was less effective and less dependent on the amount of ROS generated by the modified films (Figure 9).

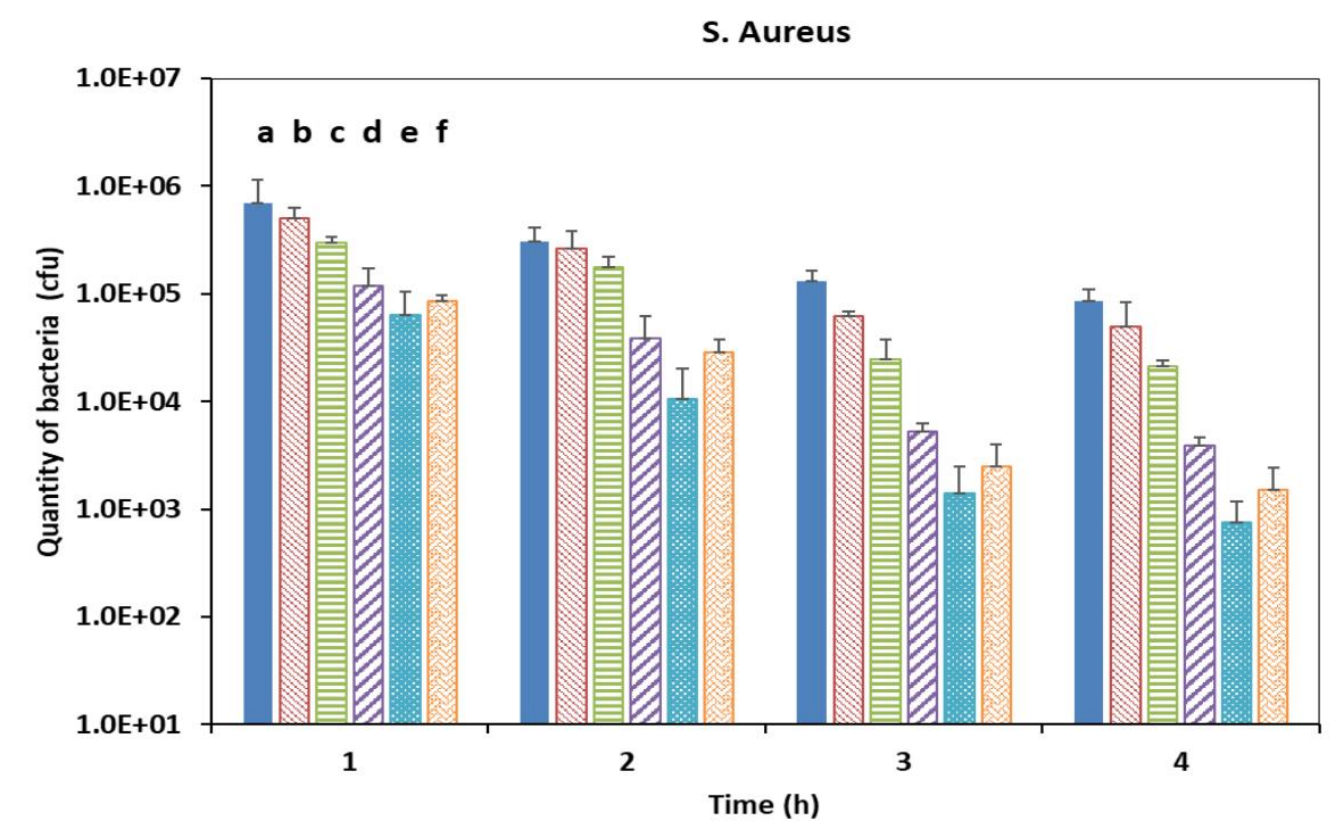

Figure 9. Antimicrobial experiments result of the antimicrobial film against E. Coli. a) PU, b) PU/citNa-AuNRs, c) PU/citNa-AuNSs, d) PU/CV, e) PU/citNaAuNRs/CV and f) PU/citNa-AuNSs/CV. All the results of PU/CV, PU/citNaAuNRs/CV and PU/citNa-AuNSs/CV were statistically different compared to PU for the same time of exposure $(p \leq 0.05)$.

Specifically, films modified with AuNRs and dye (PU/citNa-AuNRs/CV) reduced the population of bacteria by $1-\log$ unit after $1 \mathrm{~h}$ of exposure, $1.5-\log$ unit for $2 \mathrm{~h}, 2.5-\log$ unit for $3 \mathrm{~h}$, and 3-log unit for $4 \mathrm{~h}$. Films modified with AuNSs and dye (PU/citNa-AuNSs/CV) reduced by 1-log unit for $1 \mathrm{~h}$ exposure, 1.5- $\log$ unit for $2 \mathrm{~h}, 2-\log$ unit for $3 \mathrm{~h}$ and $2.5-\log$ unit for $4 \mathrm{~h}$. Film containing only dye $(\mathrm{PU} / \mathrm{CV})$ reduced the bacteria population of $0.5-\log$ unit in the first hour, 1-log unit for $2 \mathrm{~h}$ and 2-log unit for 3 and $4 \mathrm{~h}$. As stated previously, when exposing to the experimental conditions the bacteria, they were reduced of a small number (less than 1-log) for the longest time point $(4 \mathrm{~h})$. The films containing nanoparticles alone had only a minor effect on the population of bacteria, being capable to reduce their population of only 1-log for the last two time points regardless of the kind of nanoparticles used, with a result not statistically different from the polymer alone $\mathrm{p}>0.05$. As discussed earlier, $S$. aureus, as a gram positive bacteria, was not very susceptible to the ROS because of thanks to its thick bacterial barrier and to the production of radical quenching molecules in its pigmentation combined with the capability of manufacturing different types of enzymes able to decompose ROS. Our experiment confirmed this notion by showing that $S$. aureus was also less sensitive to the 
increase of ROS caused by the introduction of anisotropic nanoparticles in the film. The reduction of the gram $(+)$ bacteria population did not seems as strongly correlated to the ROS production as seen for the gram (-) bacteria. Against gram (+) bacteria CV alone seems more efficient than against E. coli, while the film containing CV and AuNSs, which was producing more ROS than any of the others had a lower impact on the activity of the film compared to AuNRs. One possible explanation for this discrepancy between ROS production and activity, could be connected to the different mechanism of action of ROS on gram (+) and gram (-) bacteria. ROS killed gram $(+)$ bacteria by damaging the DNA after passing through the pores in the bacterial barrier. While their action on gram (-) depended on their ability to damage both the layers of their bacterial membranes and thus causing the bacteria to burst. ${ }^{53}$ These considerations suggested that the ROS generated by the film were not able to pass the membranes and instead attacked the bacteria from outside. Another possible explanation could be connected on the difference of energy absorption of the coupled plasmonic system dyenanoparticles for films containing AuNRs and AuNSs (Figure 6). The difference in the energy of the light absorbed could result in a different composition of the ROS mixture generated by the system. The film, produced ROS as a mixture of several types of reactive molecules $\left({ }^{1} \mathrm{O}_{2}\right.$, $\left.\mathrm{O}_{3}{ }^{-}, \cdot \mathrm{OH}, \cdot \mathrm{OOH}, \mathrm{H}_{2} \mathrm{O}_{2}, \mathrm{CO}_{3}, \cdot \mathrm{NO}\right) .{ }^{54}$ The interaction between gold nanoparticles and dye increased the energy available to produce ROS, resulting in a greater amount of ROS produced (Figure 7) while it may also catalyse the formation of specific species, encouraging the generation of ROS with a higher formation energy. As reported in literature different types of bacteria were more vulnerable to specific types of ROS, for example gram (-) bacteria were more vulnerable to $\mathrm{OH}, \cdot \mathrm{OOH}$ radicals while gram $(+)$ were more vulnerable to ${ }^{1} \mathrm{O}_{2}, \mathrm{O}_{3}{ }^{-}$ species. $^{55}$

\section{CONCLUSIONS}

In this work we have prepared polymer films embedded with anisotropic gold nanoparticles and a photosensitizer dye. We have explored the effect of the plasmonic coupling of the nanoparticles and the dye for a normal white light activated antimicrobial function against gram $(+)$ and gram (-) bacteria. Using mathematical simulations, the plasmonic resonances of gold nanorods and nanostars was studied and validated with experimental results to understand the importance of different SPR of the particles to the plasmonic coupling with the dye. The interactions between the metal nanoparticles and the dye in the film lead to the ROS production of the films that is responsible for their efficiency against gram (+) and gram (-) bacteria. The antimicrobial film embedded with gold nanostars (AuNSs) was able to eliminate 5-log unit of 
gram (-) and 2.5-log unit of gram (+) in $4 \mathrm{~h}$ of light exposure, while the film with gold nanorods (AuNRs) eliminated 4-log unit of gram (-) and 3-log unit of gram $(+)$ in the same amount of time. The introduction of AuNSs in the film, tried for the first time, showed a boost of the antimicrobial activity against gram (-) bacteria of another order of magnitude compared to AuNRs and an increase of the ROS production of at least $0.72 \mathrm{mM} / \mathrm{h}$ of exposure. When comparing the experiments performed on gram (-) and $(+)$ bacteria, we have identified a difference on the action of ROS generated by films containing anisotropic Au nanoparticles, concluding that the gram (-) bacteria is more responsive to the ROS production than gram (+) bacteria. This observation provides strategies for future preparation of anti-bacteria films targeting different specific types of bacterial species.

\section{CONFLICTS OF INTERESTS}

There are no conflicts to declare

\section{RELATED CONTENT}

Supporting Information: are available free of charge on the ACS Publications website at DOI: UV-visible spectra of a AuNRs stabilized by CTAB after 6 months, A \& B simulation boxes of AuNRs and AuNSs, low magnification TEM pictures of AuNRs and AuNSs, UV-visible spectra of AuNRs and AuNSs stabilized with CTAB and citNa, comparison of the SPR peaks of AuNRs obtained by simulation and the UV-visible absorption of CV compared with the experimental sample, comparison of the SPR peaks of AuNSs obtained by simulations and the UV-visible absorption of CV compared with the experimental sample, $590 \mathrm{~nm}$ absorption of different concentrations of $\mathrm{CV}$ in water, calculation of the amount of $\mathrm{CV}$ diffused in the polymer in $48 \mathrm{~h}$, amount of gold encapsulated in the polymer, UV-visible absorption of spherical gold nanoparticles, UV-visible absorption of AuNRs with aspect ratio $3.8-4.2$, antimicrobial efficiency of the film in presence of different nanoparticles.

\section{ACKNOWLEDGEMENTS}

N.T. K. Thanh thanks EPSRC (EP/M018016/1 and EP/M015157/1) and AOARD (FA238617-1-4042 award) for funding, F. Rossi thanks UCL and the ARAP program of A*STAR for the scholarship and facilities.

\section{NOTE AND REFERENCES}


(1) O'Neill, J. Antimicrobial Resistance: Tackling a Crisis for the Health and Wealth of Nations; London, UK, 2014.

(2) Cecchini, M.; L. Monnet, D. Antimicrobial Resistance Tackling the Burden in the European Union; 2019.

(3) Friedman, N. D.; Temkin, E.; Carmeli, Y. The Negative Impact of Antibiotic Resistance. Clin. Microbiol. Infect. 2016, 22 (5), 416-422.

(4) Carling, P. C.; Bartley, J. M. Evaluating Hygienic Cleaning in Health Care Settings: What You Do Not Know Can Harm Your Patients. Am. J. Infect. Control 2010, 38 (5 Suppl 1), S41-50.

(5) Dancer, S. J. Controlling Hospital-Acquired Infection: Focus on the Role of the Environment and New Technologies for Decontamination. Clin. Microbiol. Rev. 2014, 27 (4), 665-690.

(6) Anderson, D. J.; Moehring, R. W.; Weber, D. J.; Lewis, S. S.; Chen, L. F.; Schwab, J. C.; Becherer, P.; Blocker, M.; Triplett, P. F.; Knelson, L. P.; Lokhnygina, Y.; Rutala, W. A.; Sexton, D. J. Effectiveness of Targeted Enhanced Terminal Room Disinfection on Hospital-Wide Acquisition and Infection with Multidrug-Resistant Organisms and Clostridium Difficile: A Secondary Analysis of a Multicentre Cluster Randomised Controlled Trial with Crossover. Lancet Infect. Dis. 2018, 18 (8), 845-853.

(7) Dancer, S. J. Controlling Hospital-Acquired Infection: Focus on the Role of the Environment and New Technologies for Decontamination. Clin. Microbiol. Rev. 2014, 27 (4), 665-690.

(8) Doan, L.; Forrest, H.; Fakis, A.; Craig, J.; Claxton, L.; Khare, M. Clinical and Cost Effectiveness of Eight Disinfection Methods for Terminal Disinfection of Hospital Isolation Rooms Contaminated with Clostridium Difficile 027. J. Hosp. Infect. 2012, $82(2), 114-121$.

(9) Irving, D.; Lamprou, D. A.; Maclean, M.; MacGregor, S. J.; Anderson, J. G.; Grant, M. H. A Comparison Study of the Degradative Effects and Safety Implications of UVC and $405 \mathrm{~nm}$ Germicidal Light Sources for Endoscope Storage. Polym. Degrad. Stab. 2016, 133, 249-254. 
(10) Abreu, A. C.; Tavares, R. R.; Borges, A.; Mergulhao, F.; Simoes, M. Current and Emergent Strategies for Disinfection of Hospital Environments. J. Antimicrob. Chemother. 2013, 68 (12), 2718-2732.

(11) Page, K.; Wilson, M.; Parkin, I. P. Antimicrobial Surfaces and Their Potential in Reducing the Role of the Inanimate Environment in the Incidence of HospitalAcquired Infections. J. Mater. Chem. 2009, 19 (23), 3818-3831.

(12) Noimark, S.; Page, K.; Bear, J. C.; Sotelo-Vazquez, C.; Quesada-Cabrera, R.; Lu, Y.; Allan, E.; Darr, J. A.; Parkin, I. P. Functionalised Gold and Titania Nanoparticles and Surfaces for Use as Antimicrobial Coatings. Faraday Discuss. 2014, 175 (0), 273-287.

(13) Perni, S.; Piccirillo, C.; Pratten, J.; Prokopovich, P.; Chrzanowski, W.; Parkin, I. P.; Wilson, M. The Antimicrobial Properties of Light-Activated Polymers Containing Methylene Blue and Gold Nanoparticles. Biomaterials 2009, 30 (1), 89-93.

(14) MacDonald, T. J.; Wu, K.; Sehmi, S. K.; Noimark, S.; Peveler, W. J.; Du Toit, H.; Voelcker, N. H.; Allan, E.; MacRobert, A. J.; Gavriilidis, A.; Parkin, I. P. ThiolCapped Gold Nanoparticles Swell-Encapsulated into Polyurethane as Powerful Antibacterial Surfaces under Dark and Light Conditions. Sci. Rep. 2016, 6 (October), $1-11$.

(15) Rossi, F.; Thanh, N. T. K.; Su, X. Di. Gold Nanorods Embedded in Polymeric Film for Killing Bacteria by Generating Reactive Oxygen Species with Light. ACS Appl. Bio Mater. 2019, 2 (7), 3059-3067.

(16) Nikoobakht, B.; El-Sayed, M. A. Preparation and Growth Mechanism of Gold Nanorods (NRs) Using Seed - Mediated Growth Method. Chem. Mater. 2003, 15 (16), 1957-1962.

(17) Pallares, R. M.; Su, X.; Lim, S. H.; Thanh, N. T. K. Fine-Tuning of Gold Nanorod Dimensions and Plasmonic Properties Using the Hofmeister Effects. J. Mater. Chem. C 2016, 4 (1), 53-61.

(18) Sahu, P.; Prasad, B. L. V. Time and Temperature Effects on the Digestive Ripening of Gold Nanoparticles: Is There a Crossover from Digestive Ripening to Ostwald Ripening? Langmuir 2014, 30 (34), 10143-10150. 
(19) Alkilany, A. M.; Murphy, C. J. Toxicity and Cellular Uptake of Gold Nanoparticles: What We Have Learned so Far? J. Nanopart. Res. 2010, 12 (7), 2313-2333.

(20) Wan, J.; Wang, J. H.; Liu, T.; Xie, Z.; Yu, X. F.; Li, W. Surface Chemistry but Not Aspect Ratio Mediates the Biological Toxicity of Gold Nanorods in Vitro and in Vivo. Sci. Rep. 2015, 5 (November 2014), 1-16.

(21) Ali, M. R. K.; Rahman, M. A.; Wu, Y.; Han, T.; Peng, X.; Mackey, M. A.; Wang, D.; Shin, H. J.; Chen, Z. G.; Xiao, H.; Ronghu, W.; Yan, T.; Shin, D. M.; El-Sayed, M. A. Efficacy, Long-Term Toxicity, and Mechanistic Studies of Gold Nanorods Photothermal Therapy of Cancer in Xenograft Mice. Proc. Natl. Acad. Sci. 2017, 114 (15), E3110-E3118.

(22) Leonov, A. P.; Zheng, J.; Clogston, J. D.; Stern, S. T.; Patri, A. K.; Wei, A. Detoxification of Gold Nanorods by Treatment with Polystyrenesulfonate. ACS Nano 2008, 2 (12), 2481-2488.

(23) Sahu, P.; Prasad, B. L. V. Time and Temperature Effects on the Digestive Ripening of Gold Nanoparticles: Is There a Crossover from Digestive Ripening to Ostwald Ripening? Langmuir 2014, 30 (34), 10143-10150.

(24) Mehtala, J. G.; Zemlyanov, D. Y.; Max, J. P.; Kadasala, N.; Zhao, S.; Wei, A. CitrateStabilized Gold Nanorods. Langmuir 2014, 30 (46), 13727-13730.

(25) ImageJ; NIH.gov; https://imagej.nih.gov/ij/.

(26) Wang, Y.; Serrano, A. B.; Sentosun, K.; Bals, S.; Liz-Marzán, L. M. Stabilization and Encapsulation of Gold Nanostars Mediated by Dithiols. Small 2015, 11 (34), 43144320.

(27) Wuithschick, M.; Birnbaum, A.; Witte, S.; Sztucki, M.; Vainio, U.; Pinna, N.; Rademann, K.; Emmerling, F.; Kraehnert, R.; Polte, J. Turkevich in New Robes: Key Questions Answered for the Most Common Gold Nanoparticle Synthesis. ACS Nano 2015, 9 (7), 7052-7071.

(28) Joseph, J.; Patel, R. M.; Wenham, A.; Smith, J. R. Biomedical Applications of Polyurethane Materials and Coatings. Trans. IMF 2018, 96 (3), 121-129.

(29) Špírková, M.; Hodan, J.; Kobera, L.; Kredatusová, J.; Kubies, D.; Machová, L.; 
Poręba, R.; Serkis, M.; Zhigunov, A.; Kotek, J. The Influence of the Length of the Degradable Segment on the Functional Properties and Hydrolytic Stability of MultiComponent Polyurethane Elastomeric Films. Polym. Degrad. Stab. 2017, 137, 216228.

(30) Turano, A.; Pirali, F. Quantification Methods in Microbiology. In Laboratory Diagnosis of Infectious Diseases; Springer New York: New York, NY, 1988; pp 8-13.

(31) Ou, B.; Hampsch-Woodill, M.; Flanagan, J.; Deemer, E. K.; Prior, R. L.; Huang, D. Novel Fluorometric Assay for Hydroxyl Radical Prevention Capacity Using Fluorescein as the Probe. J. Agric. Food Chem. 2002, 50 (10), 2772-2777.

(32) Alberto, D.; Carmen, G.-C.; Bartolomé, B. Extending Applicability of the Oxygen Radical Absorbance Capacity (ORAC-Fluorescein) Assay. J. Agric. Food Chem. 2004, $52(1), 48-54$.

(33) Song, L.; Varma, C. A. G. O.; Verhoeven, J. W.; Tanke, H. J. Influence of the Triplet Excited State on the Photobleaching Kinetics of Fluorescein in Microscopy. Biophys. J. 1996, 70 (6), 2959-2968.

(34) Nakahara, R.; Kashitani, S.; Hayakawa, K.; Kitani, Y.; Yamaguchi, T.; Fujita, Y. Fluorophotometric Determination of Hydrogen Peroxide with Fluorescin in the Presence of Cobalt (II) and Reaction against Other Reactive Oxygen Species. $J$. Fluoresc. 2009, 19 (5), 769-775.

(35) Song, L.; Hennink, E. J.; Young, I. T.; Tanke, H. J. Photobleaching Kinetics of Fluorescein in Quantitative Fluorescence Microscopy. Biophys. J. 1995, 68 (6), 25882600 .

(36) Arik, M.; Çelebi, N.; Onganer, Y. Fluorescence Quenching of Fluorescein with Molecular Oxygen in Solution. J. Photochem. Photobiol. A Chem. 2005, 170 (2), $105-$ 111.

(37) Joshi, A. A.; Locke, B. R.; Arce, P.; Finney, W. C. Formation of Hydroxyl Radicals, Hydrogen Peroxide and Aqueous Electrons by Pulsed Streamer Corona Discharge in Aqueous Solution. J. Hazard. Mater. 1995, 41 (1), 3-30.

(38) Špalek, O.; Balej, J.; Paseka, I. Kinetics of the Decomposition of Hydrogen Peroxide 
in Alkaline Solutions. J. Chem. Soc. Faraday Trans. 1 Phys. Chem. Condens. Phases 1982, $78(8), 2349$.

(39) Guerrero-Martínez, A.; Barbosa, S.; Pastoriza-Santos, I.; Liz-Marzán, L. M. Nanostars Shine Bright for You. Colloidal Synthesis, Properties and Applications of Branched Metallic Nanoparticles. Curr. Opin. Colloid Interface Sci. 2011, 16 (2), 118-127.

(40) Hamester, L. S.; Muñoz, P. A. R.; Canevarolo, S. V. A New Device for In-Line Colorimetric Quantification of Polypropylene Degradation under Multiple Extrusions. Polym. Test. 2015, 41, 117-123.

(41) Reyes, M.; Piotrowski, M.; Ang, S. K.; Chan, J.; He, S.; Chu, J. J. H.; Kah, J. C. Y. Exploiting the Anti-Aggregation of Gold Nanostars for Rapid Detection of Hand, Foot, and Mouth Disease Causing Enterovirus 71 Using Surface-Enhanced Raman Spectroscopy. Anal. Chem. 2017, 89 (10), 5373-5381.

(42) Nikoobakht, B.; El-Sayed, M. A. Surface-Enhanced Raman Scattering Studies on Aggregated Gold Nanorods. J. Phys. Chem. A 2003, 107 (18), 3372-3378.

(43) Chen, H.; Ming, T.; Zhao, L.; Wang, F.; Sun, L.-D.; Wang, J.; Yan, C.-H. PlasmonMolecule Interactions. Nano Today 2010, 5 (5), 494-505.

(44) Abbot, J.; Brown, D. G. Stabilization of Iron-Catalysed Hydrogen Peroxide Decomposition by Magnesium. Can. J. Chem. 1990, 68 (9), 1537-1543.

(45) Youtsey, K. J.; Grossweiner, L. I. Photochemical Reactions of Fluorescein Dyes with Hydrogen Peroxide. J. Phys. Chem. 1969, 73 (2), 447-448.

(46) Rezende, F.; Brandes, R. P.; Schröder, K. Detection of Hydrogen Peroxide with Fluorescent Dyes. Antioxid. Redox Signal. 2018, 29 (6), 585-602.

(47) Di Pilla, S. U.S. Standards and Guidelines; 2009.

(48) Silhavy, T.; Kahne, D.; Walker, S. The Bacterial Cell Envelope. Cold Spring Harb. Perspect. Biol. 2010, 2 (5), 1-16.

(49) Imlay, J. A. Cellular Defenses against Superoxide and Hydrogen Peroxide James. 2008, 77, 755-776.

(50) Liu, G. Y.; Essex, A.; Buchanan, J. T.; Datta, V.; Hoffman, H. M.; Bastian, J. F.; 
Fierer, J.; Nizet, V. Staphylococcus Aureus Golden Pigment Impairs Neutrophil Killing and Promotes Virulence through Its Antioxidant Activity. J. Exp. Med. 2005, 202 (2), 209-215.

(51) Gaupp, R.; Ledala, N.; Somerville, G. A. Staphylococcal Response to Oxidative Stress. Front. Cell. Infect. Microbiol. 2012, 2, 33.

(52) Perni, S.; Piccirillo, C.; Kafizas, A.; Uppal, M.; Pratten, J.; Wilson, M.; Parkin, I. P. Antibacterial Activity of Light-Activated Silicone Containing Methylene Blue and Gold Nanoparticles of Different Sizes. J. Clust. Sci. 2010, 21 (3), 427-438.

(53) Han, L.; Patil, S.; Boehm, D.; Milosavljević, V.; Cullen, P. J.; Bourke, P. Mechanisms of Inactivation by High-Voltage Atmospheric Cold Plasma Differ for Escherichia Coli and Staphylococcus Aureus. Appl. Environ. Microbiol. 2016, 82 (2), 450-458.

(54) Al Housari, F.; Vione, D.; Chiron, S.; Barbati, S. Reactive Photoinduced Species in Estuarine Waters. Characterization of Hydroxyl Radical, Singlet Oxygen and Dissolved Organic Matter Triplet State in Natural Oxidation Processes. Photochem. Photobiol. Sci. 2010, 9 (1), 78-86.

(55) Huang, L.; Xuan, Y.; Koide, Y.; Zhiyentayev, T.; Tanaka, M.; Hamblin, M. R. Type I and Type II Mechanisms of Antimicrobial Photodynamic Therapy: An in Vitro Study on Gram-Negative and Gram-Positive Bacteria. Lasers Surg. Med. 2012, 44 (6), 490499. 

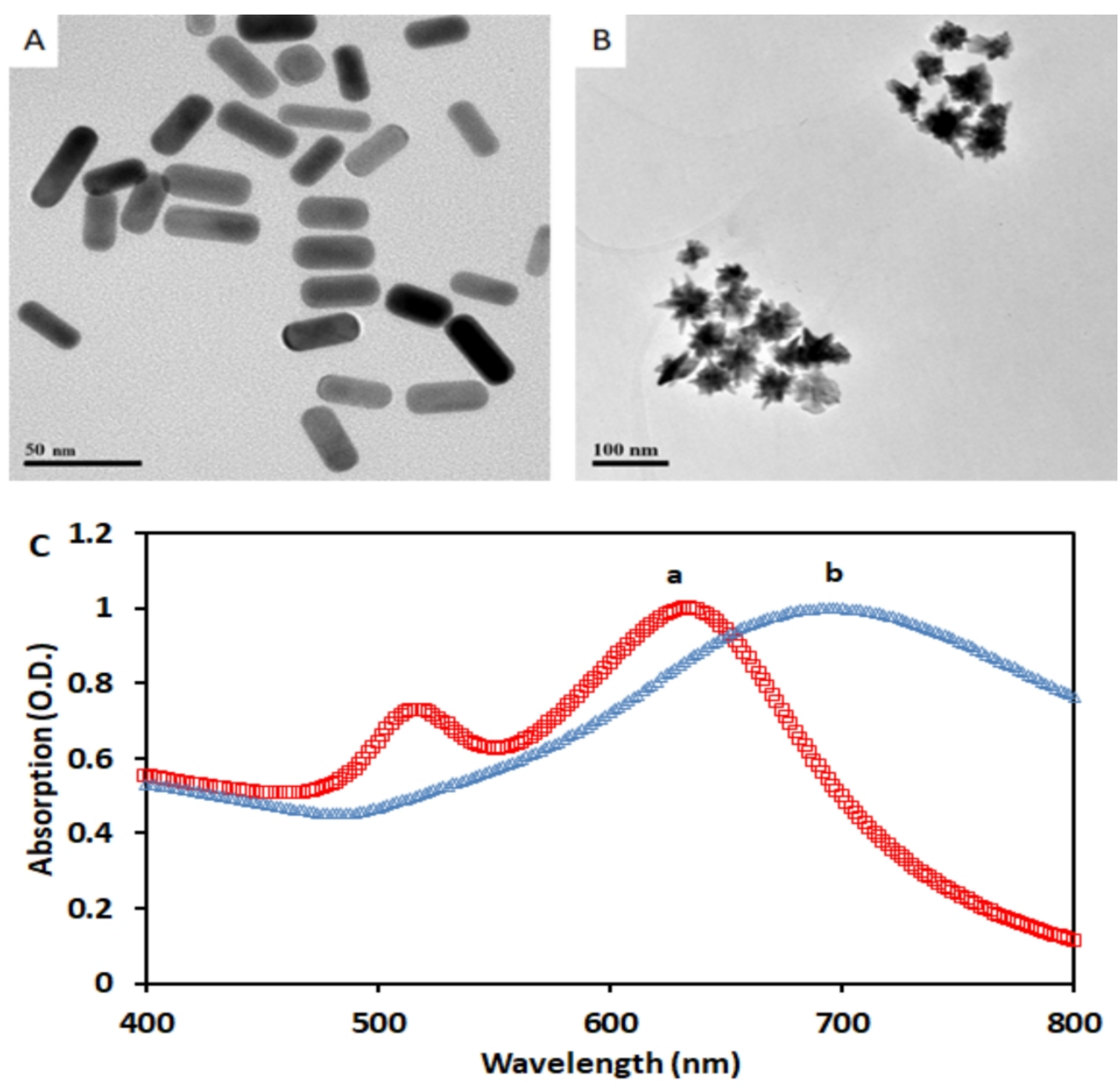

Figure 1. Characterization of AuNRs and AuNSs: A) TEM picture of AuNRs 75k magnifications, B) TEM picture of AuNSs 23.5k magnifications and C) UV-visible spectra of citNa-AuNRs (a) and citNa-AuNSs (b).

$125 \times 119 \mathrm{~mm}(1016 \times 1016$ DPI $)$ 


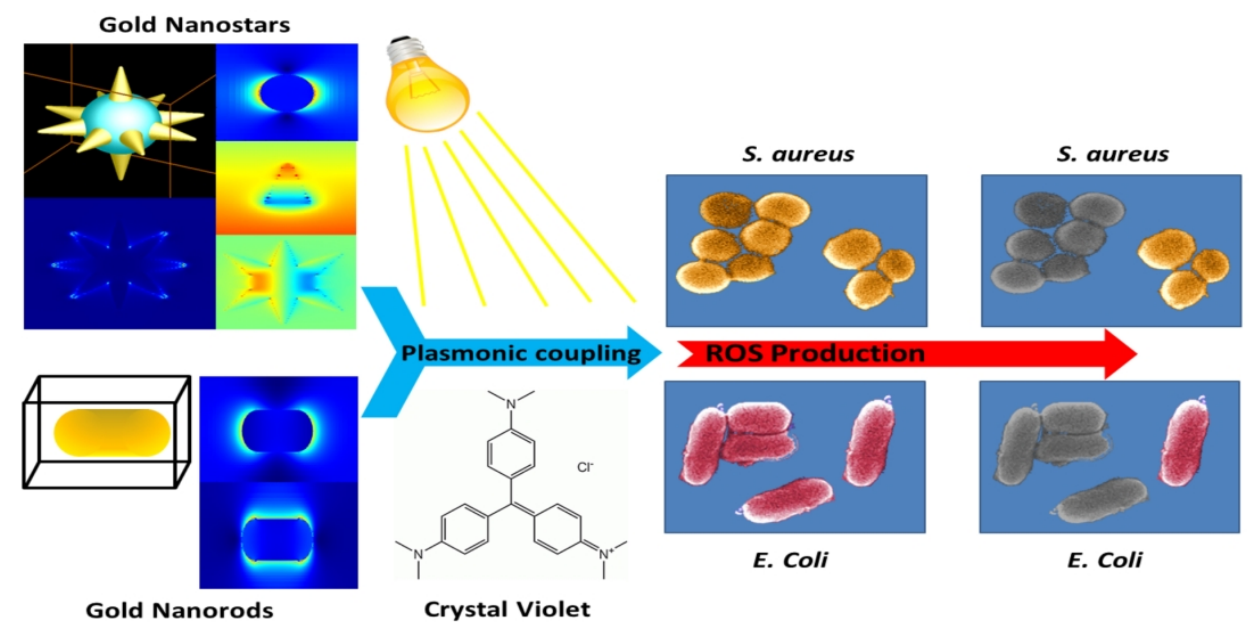

Understanding the plasmonic interaction between anisotropic nanoparticles and dye to boost the light activated sterilization of surfaces

$80 \times 40 \mathrm{~mm}(635 \times 635 \mathrm{DPI})$ 


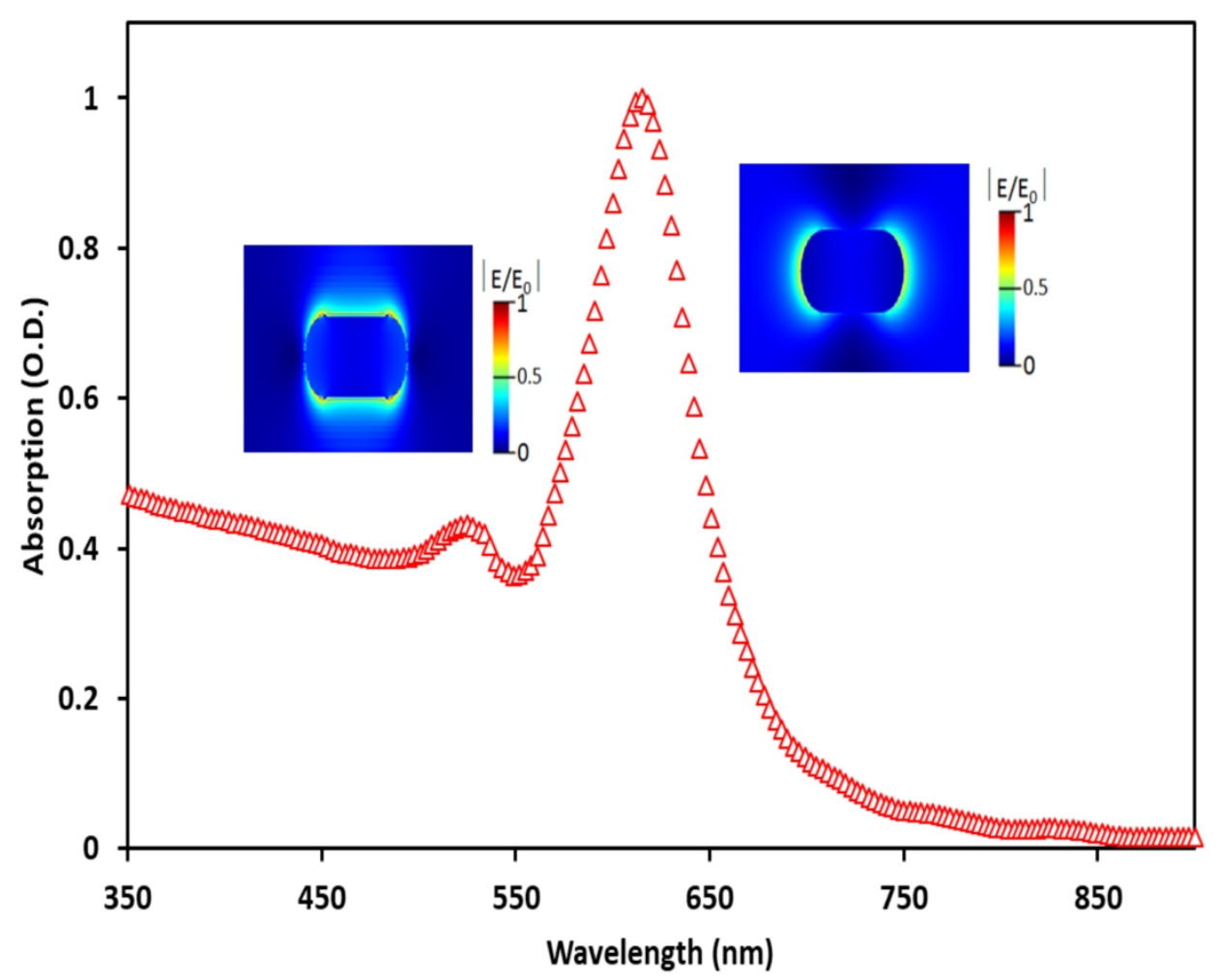

Figure 2. Electrical field simulation for AuNRs $(31.8 \mathrm{~nm} \times 16.1 \mathrm{~nm}$ ) stabilized with thiol-PEG-OMe. $80 \times 65 \mathrm{~mm}(1016 \times 1016$ DPI $)$ 

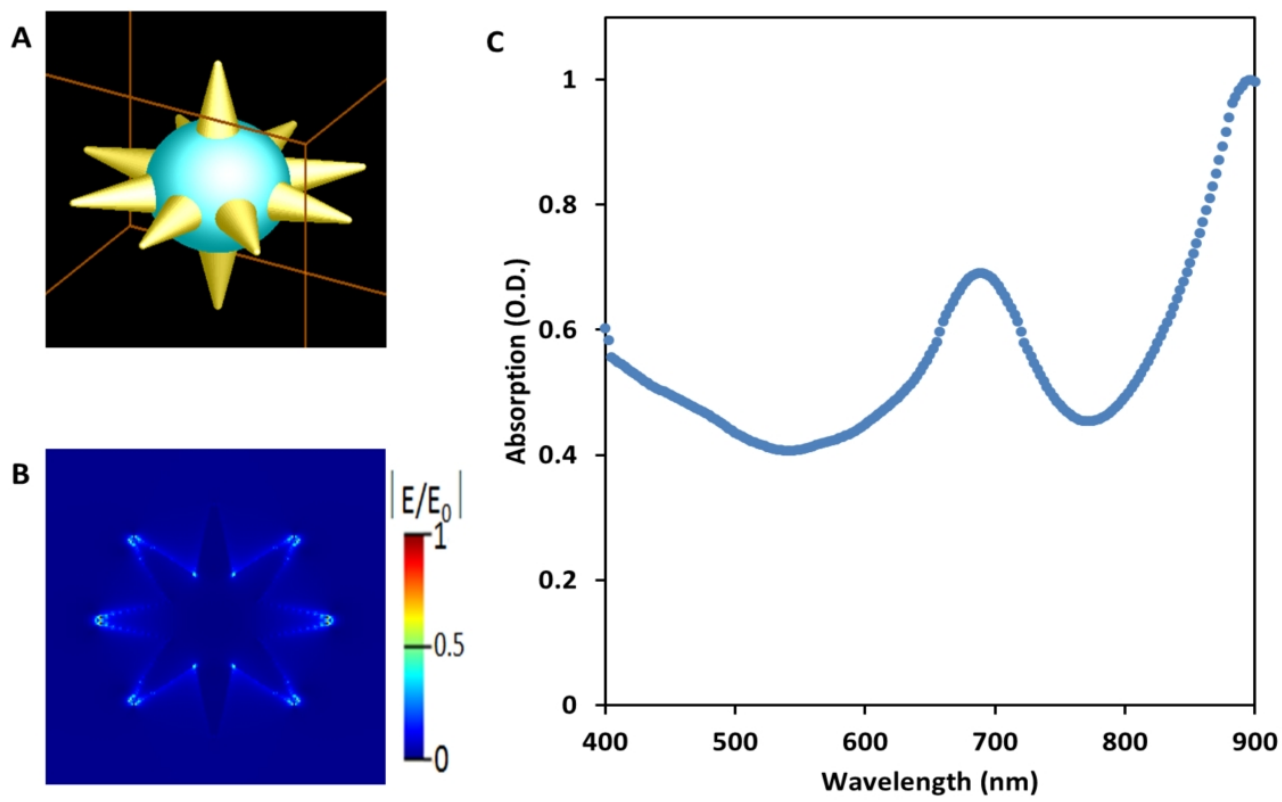

Figure 3. Simulation of the SPR of the electrical field around AuNSs with $35.6 \mathrm{~nm}$ core with $16.1 \mathrm{~nm}$ spikes, stabilized with PEG. A) Model of the nanostar used in the simulation; B) Graphical representation of the potential fluctuation of the electrical field on the surface of the particles; $\mathrm{C}$ ) Simulated spectrum of the nanostars dispersion.

$125 \times 80 \mathrm{~mm}(1016 \times 1016$ DPI $)$ 


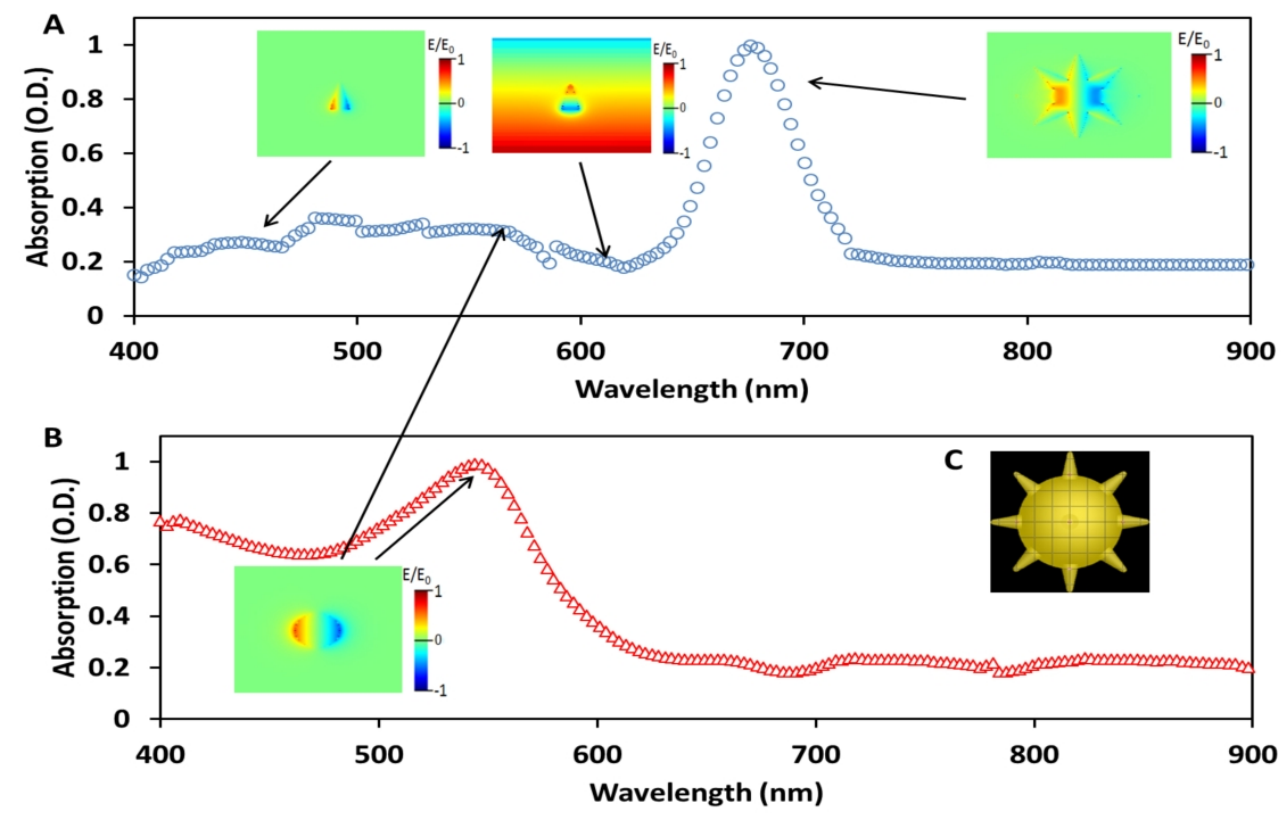

Figure 4. Electrical field resonance simulation for AuNSs (50 nm core with $10 \mathrm{~nm}$ spikes) stabilized with PEG A) simulated spectra of the spike system and B) simulated spectra of the core C) model of the AuNSs used for the simulation.

$125 \times 80 \mathrm{~mm}(1016 \times 1016 \mathrm{DPI})$ 

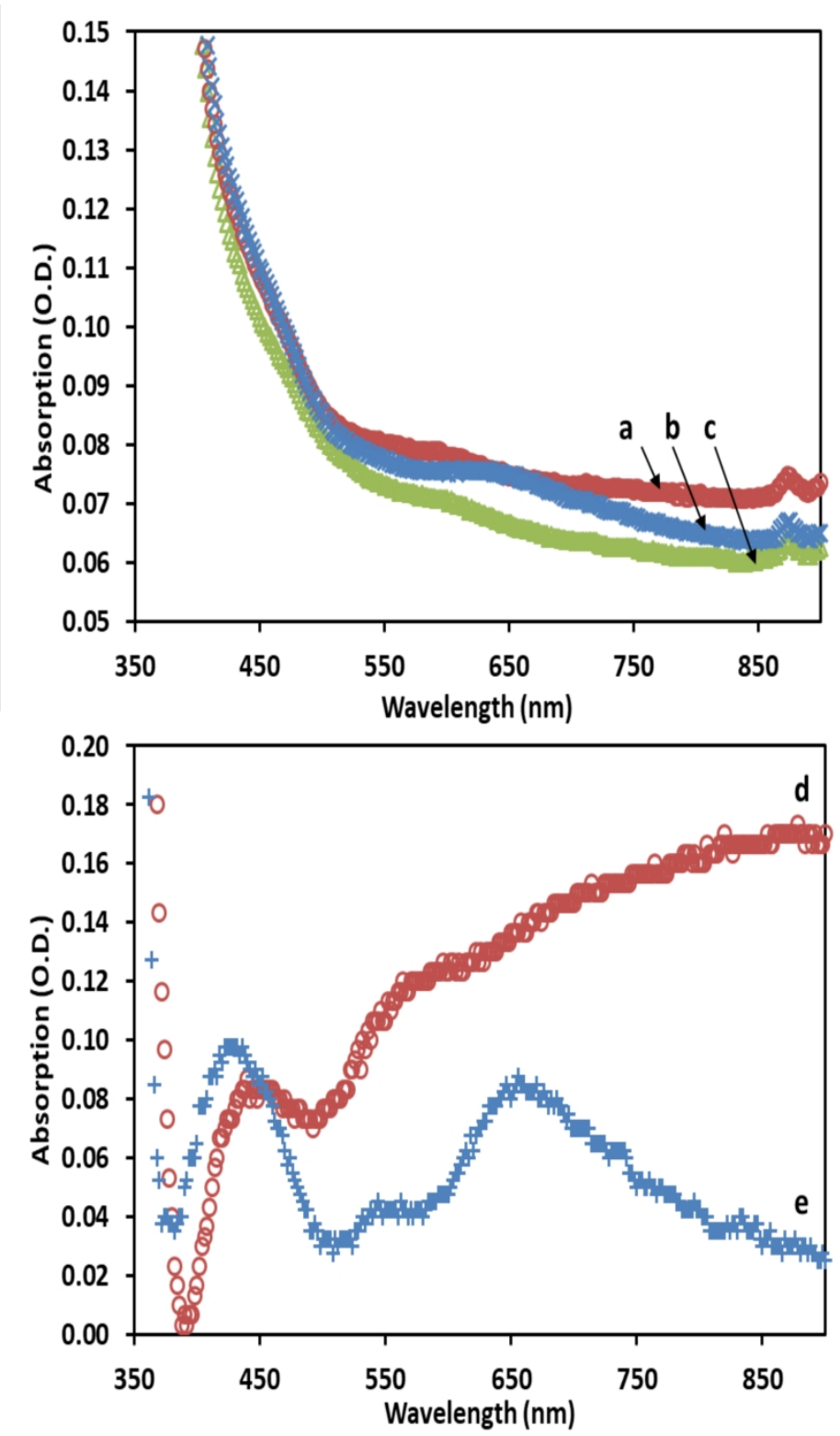

Figure 5. UV-visible spectra of a) PU/citNa-AuNSs, b) PU/citNa-AuNRs, c) PU, d) subtraction curve between $\mathrm{PU} /$ citNa-AuNSs and PU, and e) subtraction curve between PU/citNa-AuNRs and PU.

$80 \times 130 \mathrm{~mm}(1016 \times 1016 \mathrm{DPI})$ 


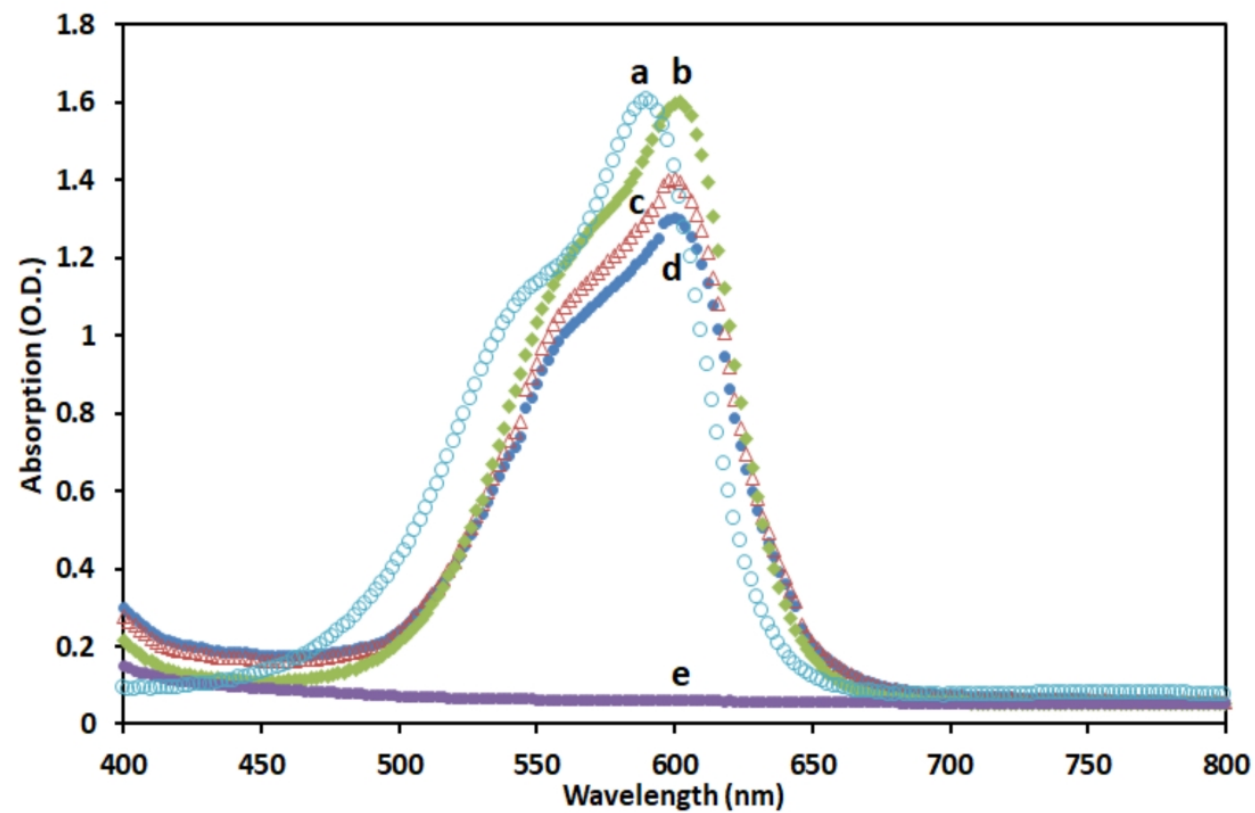

Figure 6. UV-visible spectra of a) $35 \mu \mathrm{M} \mathrm{CV}$ solution in water, b) $1 \mathrm{mM} \mathrm{CV}$ diffused in PU for $48 \mathrm{~h}$ (PU/CV film), c) PU/CitNa-AuNSs/CV film, d) PU/CitNa-AuNRs/CV film and e) PU alone.

$125 \times 80 \mathrm{~mm}(1016 \times 1016 \mathrm{DPI})$ 
Figure 7. Fluorescence intensity against the estimated concentration of ROS by measuring the intensity of sodium fluorescein solution in the presence of different concentration of a) $\mathrm{H} 2 \mathrm{O} 2$, b) $\mathrm{PU} / \mathrm{CV}$, c) PU/citNaAuNRs/CV, d) PU/citNa-AuNSs/CV. 
Figure 8. Antimicrobial experiments result of the antimicrobial film against E. Coli. a) PU, b) PU/citNaAuNRs, c) PU/citNa-AuNSs, d) PU/CV, e) PU/citNa-AuNRs/CV and f) PU/citNa-AuNSs/CV. All the results of $\mathrm{PU} /$ citNa-AuNRs/CV and PU/citNa-AuNSs/CV were statistically different compared to PU for the same time of exposure $(p \leq 0.001)$

$125 \times 80 \mathrm{~mm}(1016 \times 1016 \mathrm{DPI})$

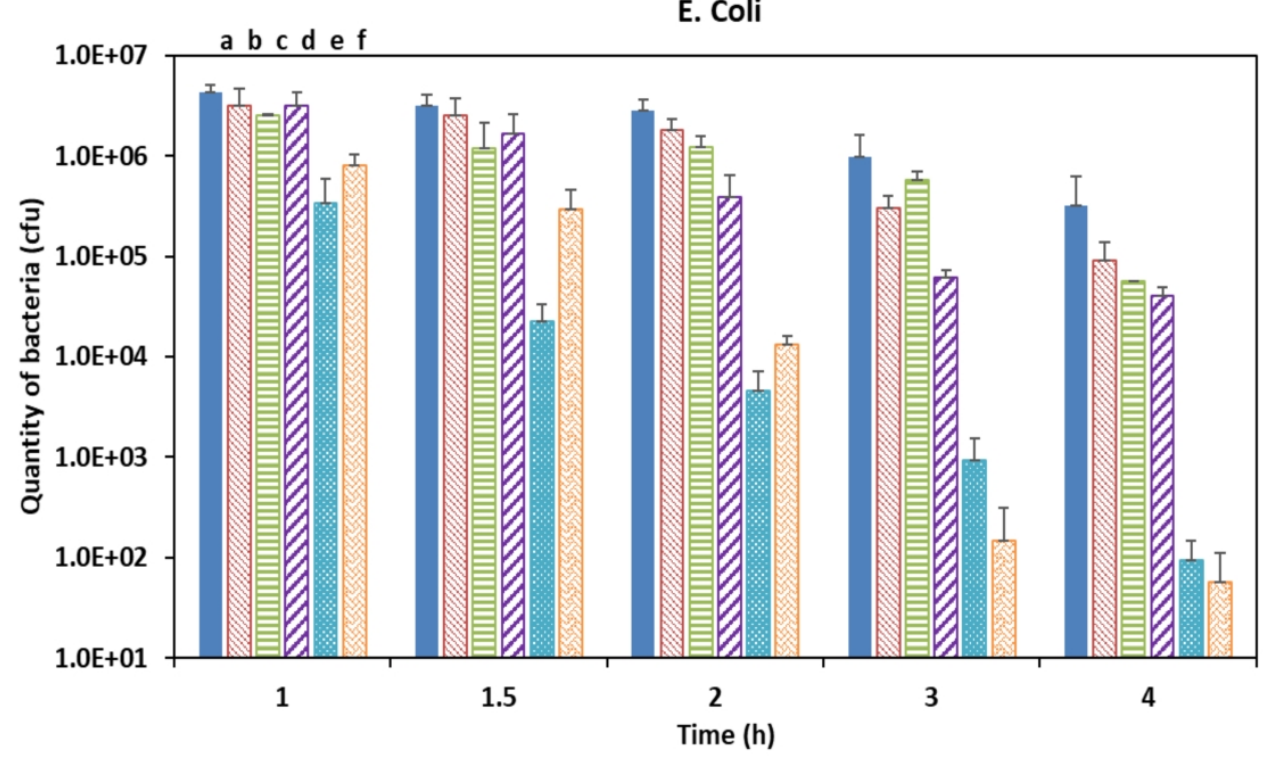


Figure 9. Antimicrobial experiments result of the antimicrobial film against E. Coli. a) PU, b) PU/citNaAuNRs, c) PU/citNa-AuNSs, d) PU/CV, e) PU/citNa-AuNRs/CV and f) PU/citNa-AuNSs/CV. All the results of $\mathrm{PU} / \mathrm{CV}, \mathrm{PU} / \mathrm{citNa}-\mathrm{AuNRs} / \mathrm{CV}$ and PU/CitNa-AuNSs/CV were statistically different compared to PU for the same time of exposure $(p \leq 0.05)$.

$125 \times 80 \mathrm{~mm}(1016 \times 1016 \mathrm{DPI})$

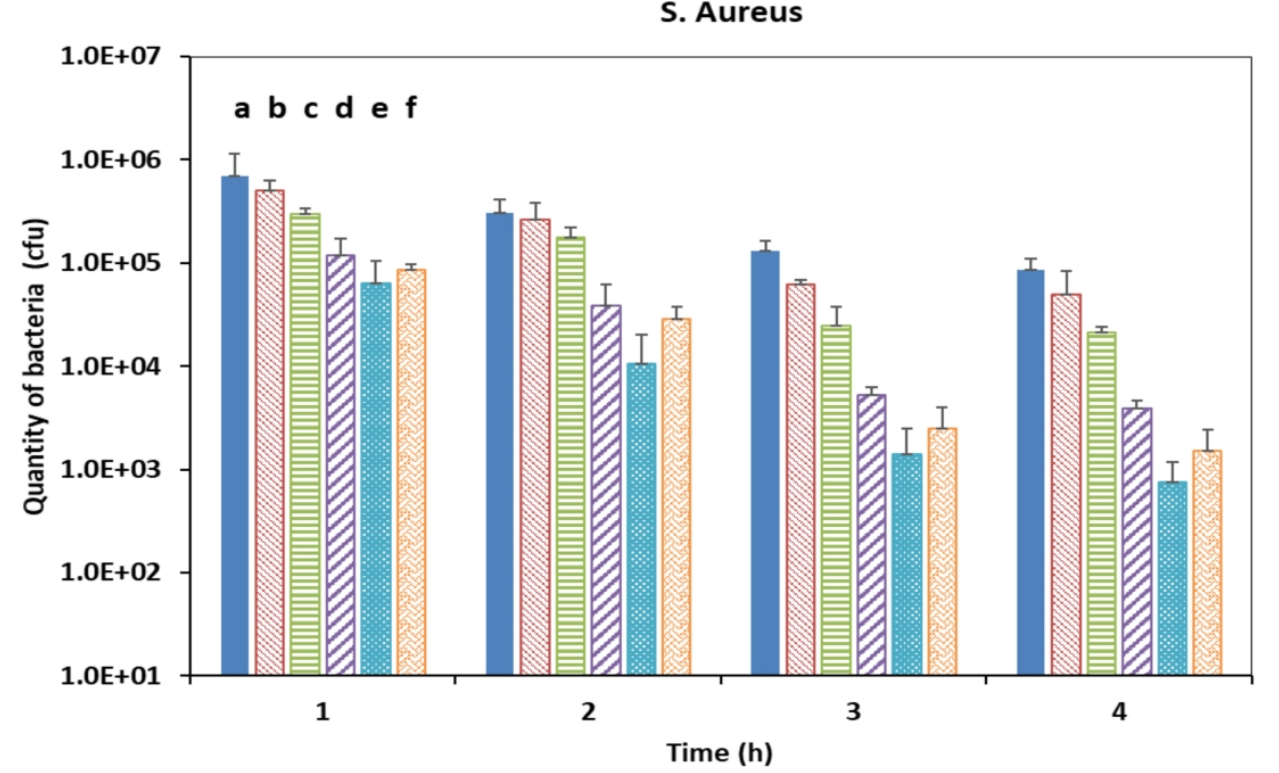

